San Jose State University

SJSU ScholarWorks

Master's Theses

Master's Theses and Graduate Research

1989

\title{
Investigation of the zinc-iron potential reversal and its application to corrosion in domestic hot water systems
}

Yao-Tzung Roger Shih

San Jose State University

Follow this and additional works at: https://scholarworks.sjsu.edu/etd_theses

\section{Recommended Citation}

Shih, Yao-Tzung Roger, "Investigation of the zinc-iron potential reversal and its application to corrosion in domestic hot water systems" (1989). Master's Theses. 3224.

DOI: https://doi.org/10.31979/etd.ywf6-z3zd

https://scholarworks.sjsu.edu/etd_theses/3224

This Thesis is brought to you for free and open access by the Master's Theses and Graduate Research at SJSU ScholarWorks. It has been accepted for inclusion in Master's Theses by an authorized administrator of SJSU ScholarWorks. For more information, please contact scholarworks@sjsu.edu. 


\section{INFORMATION TO USERS}

The most advanced technology has been used to photograph and reproduce this manuscript from the microfilm master. UMI films the text directly from the original or copy submitted. Thus, some thesis and dissertation copies are in typewriter face, while others may be from any type of computer printer.

The quality of this reproduction is dependent upon the quality of the copy submitted. Broken or indistinct print, colored or poor quality illustrations and photographs, print bleedthrough, substandard margins, and improper alignment can adversely affect reproduction.

In the unlikely event that the author did not send UMI a complete manuscript and there are missing pages, these will be noted. Also, if unauthorized copyright material had to be removed, a note will inaiicate the deletion.

Oversize materials (e.g., maps, drawings, charts) are reproduced by sectioning the original, beginning at the upper left-hand corner and continuing from left to right in equal sections with small overlaps. Each original is also photographed in one exposure and is included in reduced form at the back of the book.

Photographs included in the original manuscript have been reproduced xerographically in this copy. Higher quality $6^{\prime \prime} \times 9^{\prime \prime}$ black and white photographic prints are available for any photographs or illustrations appearing in this copy for an additional charge. Contact UMI directly to order.

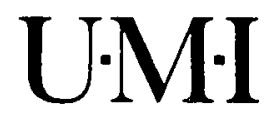

University Microfilms International

A Bell \& Howell Infermation Company 300 North Zeeb Road. Ann Arbor, MI 48106-1346 USA

$313 / 761-4700 \quad 800 / 521-0600$ 

Order Number 1399650

Investigation of the zinc-iron potential reversal and its application to corrosion in domestic hot water systems

Shih, Yao-Tzung Roger, M.S.

San Jose State University, 1989

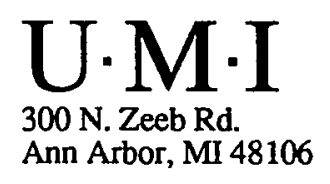


- 
INVESTIGATION OF THE ZINC-IRON POTENTIAL REVERSAL AND ITS APPLICATION TO CORROSION IN DOMESTIC HOT WATER SYSTEMS

\author{
A Thesis \\ Presented to \\ The Faculty of the Department of Materials Engineering \\ San Jose State University \\ In Partial Fulfillment \\ of the Requirements for the Degree \\ Master of Science
}

By

Yao-Tzung Roger Shih

December, 1989 
APPROVED FOR THE DEPARTMENT OF MATERIALS ENGINEERING

Lad M. Anderson

Dr. Robert N. Anderson
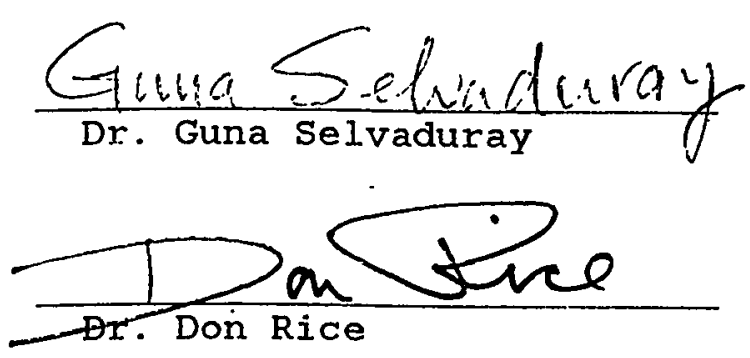

APPROVED FOR THE UNIVERSITY

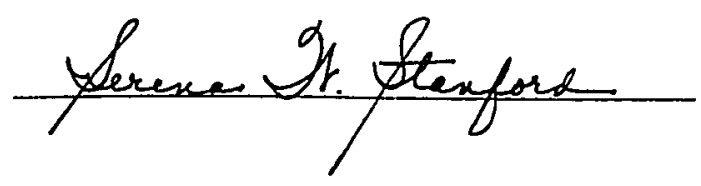




\begin{abstract}
INVESTIGATION OF THE ZINC-IRON POTENTIAL REVERSAL AND ITS APPLICATION TO CORROSION IN DOMESTIC HOT WATER SYSTEMS by Yao-Tzung R. Shih

Experience has shown that galvanized steel pipes used in hot water systems fail more rapidly than those in cold water systems. This fact has been attributed to the occurrence of a potential reversal for zinc and iron at temperatures of $60^{\circ} \mathrm{C}$ or more. The mechanism by which zinc protects steel from corrosion in an aqueous environment was studied. The temperature dependence of the standard electrochemical potentials for zinc and iron was computed theoretically, and also measured experimentally. The results of these two approaches show that the electrochemical potentials for these two species do not reverse. However, the corrosion potentials, which strongly depend on the environment, may reverse in aerated hot waters, and the occurrence of this reversal was interpreted in this study. Oxygen polarization on the zinc surface, and the nature of the corrosion products formed, was found to be a determining factor in the occurrence of the corrosion potential reversal. Temperature was found to be of secondary importance.
\end{abstract}




\section{ACKNOWLEDGEMENTS}

I am indebted to Associate Professor Guna Selvaduray, my advisor, for his persistent guidance and constant help, to Dr. Steve Melmecki of Hewlett Packard Sunnyvale Printed Circuit Operation, for his counsel and advice in setting up the experiment, to Dr. Joseph Gordon of IBM Almaden Research Center, for his critical comments, to Professor Robert $\mathrm{N}$. Anderson for his valuable comments and for being Chair of my thesis committee, and to Dr. Don Rice of Hewlett Packard Laboratories, for his guidance throughout the course of this study .

I thank my parents, Mr. and Mrs. Chung-Li shih, and my wife, Bih-Ling, for their endearing support and patience throughout the duration of this study. 
Page

ABSTRACT

ACKNOWLEDGEMENTS

iv

TABLE OF CONTENTS

$\mathrm{v}$

LIST OF EIGURES

ix

LIST OF TABLES

$\mathbf{x}$

Chapter 1. Introduction

Chapter 2. Corrosion Protection of Steel by Zinc and Electrode Kinetics

2-1 Corrosion Mechanism in Aqueous Environment

2-2 Definitions of Electrochemical Potential of Zinc and Iron

2-3 Necessary Conditions for Corrosion to Occur

2-5 Polarization Effect of an Electrode

2-5-1 Activation Polarization

2-5-2 Concentration Polarization

2-5-3 Combined Polarization

2-6 Mixed-Potential Theory

2-7 Corrosion Potential of Metal in Aqueous Environment

3-1 Effect of Temperature

3-2 Effect of Dissolved Oxygen

3-3 Effect of Water Composition 
Page

3-4 The "Potential Reversal" Hypothesis

3-5 Implications of the Term "Potential

37 Reversal"

Chapter 4. Problems of "Potential Reversal"

Hypothesis and Research Objective

Chapter 5. Research Methods of "Potential Reversal". 42

5-1 Thermodynamic Evaluation of Occur- 42 rence of Potential Reversal

5-1-1 Calculation of Standard Free Energy Change of Formation of Compound

5-1-2 Calculation of Standard Free Energy Change of Reaction

5-2 Experimental Determination of Standard Electrochemical Potential for Zinc and Iron

5-2-1 Preparation of Metal Electrodes 54

5-2-2 Preparation of Electrolytes 55

5-2-3 Instrumentation 57

Chapter 6. Results of Research Investigation 62

6-1 Calculation Results of Standard 62

Free Energy Change of Reactions

6-2 Standard Electrochemical Potential 69 of Zinc of Iron 
$\underline{\text { Page }}$

7-1 Corrosion Potential of Steel and Zinc in Aqueous Environment

7-1-1 Corrosion Potential of steel

7-1-2 Corrosion Potential of Zinc in Deaerated Water

7-1-3 Corrosion Potential of Zinc in Aerated Water

7-2 Effect of Dissolved Oxygen on

Corrosion Potential of Zinc

7-3 Effect of Temperature on Corrosion Potential of Zinc

7-3-1 Temperature Effect on Eormation of Corrosion Product

7-3-2 Temperature Effect on Areas of Cathode and Anode

7-4 Effect of Water Composition on Corrosion Potential of Zinc

7-5 Interpretation of Previous Investigations

Chapter 8. Conclusion

References

Bibliography

Appendix A. Standard enthalpies $\mathrm{H}^{0}{ }_{298}$ and standard entropies $S^{0}{ }_{298}$ of zinc, iron, and their compounds.

Appendix B. Standard heat capacities of zinc, iron, and their compounds.

Appendix C. Formation reactions of $\mathrm{zinc}$ and iron compounds. 


\section{Page}

Appendix D. Standard Gibbs free energy change of

112 formation for zinc, iron, and compounds at $20^{\circ} \mathrm{C} \leq \mathrm{T} \leq 80^{\circ} \mathrm{C}$.

Appendix E. Possible effect of the pH of solution on the $\mathrm{Zn}(\mathrm{OH})_{2}$ - $\mathrm{ZnO}$ transformation reaction. 


\section{LIST OF EIGURES}

Page

Figure 1. Corrosion triangle showing the three components necessary for corrosion to occur.

Figure 2. Schematic representation of the . potential $\mathrm{E}$ of an electrode under activation polarization.

Figure 3. Schematic representation of the potential $\mathrm{E}$ of an electrode under activation and concentration polarizations.

Figure 4. Schematic representation of the electrode behavior of a metal $M$ in a corrosive environment.

Figure 5. Exploded view of specimen holder. 56

Figure 6. View of model 273 potentiostat and 59 system assembly.

Figure 7. Schematic diagram of corrosion cell 60 system.

Figure 8. Schematic diagram of system assembly. 61

Figure 9. The experimental and published values 74 of the standard electrode potentials of zinc and iron at various temperatures vs. NHE at $25^{\circ} \mathrm{C}$.

Eigure 10. The electrode potential $\mathrm{E}$ of $\mathrm{zinc}$ in deaerated water at $25^{\circ} \mathrm{C}$. 


\section{LIST OE TABLES}

Page

Table 1. Standard electrode potentials $\mathrm{V}^{0}$ of some electrode reactions at $25^{\circ} \mathrm{C}$.

Table 2. Standard electrochemical potential, Tafel coefficients $B$ and exchange current densities $j_{0}$ for some electrode systems in aqueous solutions at $25^{\circ} \mathrm{C}$.

Table 3. Oxidation reactions of $z$ inc and iron in an aqueous environment.

Table 4. Oxidation-reduction reactions of (elemental) zinc and iron compounds in an aqueous environment.

Table 5. Mean ionic molal activity coefficients, $\tau$, of 0.010 molal zinc chloride at $10^{\circ} \mathrm{C} \leq \mathrm{T} \leq 40^{\circ} \mathrm{C}$.

Table 6. Standard free energy changes of reactions for the compounds of zinc and iron formed in aqueous environment at $20^{\circ} \mathrm{C} \leq \mathrm{T} \leq 80^{\circ} \mathrm{C}$.

Table 7. Standard free energy change of reaction $(>-20 \mathrm{Kcal} / \mathrm{mole}$ of $\mathrm{zinc})$ for redox reactions between (elemental) zinc and iron compounds in an aqueous environment at $20^{\circ} \mathrm{C} \leq \mathrm{T} \leq 80^{\circ} \mathrm{C}$.

Table 8. Standard free energy change of reaction (between -50 and $-20 \mathrm{Kcal} / \mathrm{mole}$ of $\mathrm{zinc}$ ) for redox reactions between (elemental) zinc and iron compounds, in an aqueous environment.

Table 9. Standard free energy change of reaction $(<-50 \mathrm{Kcal} / \mathrm{mole}$ of zinc) for redox reactions between (elemental) zinc and iron compounds, in an aqueous environment at $20^{\circ} \mathrm{C} \leq \mathrm{T} \leq 80^{\circ} \mathrm{C}$.

Table 10. Experimentally determined values and published values for the standard electrochemical potential of zinc vs. NHE at $25^{\circ} \mathrm{C}$. 
Page

Table 11. Experimentally determined values and published values for the standard electrochemical potential of iron vs. NHE at $25^{\circ} \mathrm{C}$.

Table 12. Standard electrochemical potential differences between zinc and iron.

Table 13. Standard Gibbs Free energy change of zinc hydroxide and zinc oxide transformation reaction at $20^{\circ} \mathrm{C} \leq \mathrm{T} \leq 80^{\circ} \mathrm{C}$.

Table 14. Pilling-Bedworth ratios for zinc compounds, aluminum oxide, and titanium oxide. 
Chapter 1. INTRODUCTION

Corrosion of a metal is the destructive attack of the metal surface by chemical or electrochemical reaction with its environment. It is therefore a troublesome and costly phenomenon. Billions of dollars are spent annually to prevent, retard, or mitigate the effects of corrosion. Corrosion of water systems affects nearly everyone in a modern industrialized society, since water is a necessity in every household and every industrial plant.

Water systems can be categorized into industrial and domestic water systems. Corrosion in the latter needs a great deal of attention due to the large volumes of water used, and its potential effect on human life. Galvanized steel pipe has been one of the two materials traditionally used for hot and cold domestic water supplies, the other material being copper. However, there have been several reports of unsatisfactory performance of galvanized steel pipes in hot water systems ${ }^{(1-6)}$. They imply that zinc does not effectively protect the steel in hot water systems. The effectiveness of the zinc coating to protect steel from corrosion in hot water systems has therefore been studied by various investigators ${ }^{(1-9)}$. However, these studies do not appear to be conclusive. They especially lack in reconciling theoretical predictions with experimental findings. 
This study was therefore undertaken to investigate the capability of zinc to galvanically protect steel at temperatures ranging from 20 to $80^{\circ} \mathrm{C}$. The apnroach has been to determine theoretical predictions based upon thermodynamic data, conduct physical measurements, and determine if the two agree or not.

Chapter 2 discusses the theoretical aspects pertaining to galvanic protection of steel by zinc and electrode kinetics. Chapter 3 describes the studies pertaining to the performance of galvanized steel in aqueous environment and the conclusion drawn from them by the previous investigators. Chapter 4 discusses the problems of this conclusion, which is the occurrence of potential reversal between zinc and iron in aerated water at temperatures of $60^{\circ} \mathrm{C}$ or above, and the research objective of this study. Chapter 5 describes the research pertaining to "potential reversal," by means of theoretical calculations and physical measurements of the electrochemical potential. Chapter 6 shows the results of the research. Chapter 7 discusses the results and interprets the finding of potential reversal by previous investigators. Chapter 8 presents the conclusions of this study. 
Chapter 2. CORROSION PROTECTION OF STEEL BY Z INC AND ELECTRODE KINETICS

It is known that steel pipes for water supplies will last longer in service if the pipe surface is coated with zinc. Knowing why corrosion occurs and the mechanisms by which it occurs in aqueous solutions will help understand how zinc is expected to protect the steel from corrosion.

\section{2-1 Corrosion Mechanism in Aqueous Environment}

In order for corrosion to occur, the cationic species first needs to be ionized, followed by its dissolution into the aqueous environment. In the case of steel or iron in an aqueous environment, the ionization and dissolution reactions can be expressed simultaneously as the following oxidation reaction of iron:

$$
\mathrm{Ee}(\mathrm{s})=\mathrm{Fe}^{2+}(\mathrm{aq})+2 \mathrm{e}^{-}
$$

It is the ferrous ion that dissolves in the aqueous environment. For the reaction to proceed, both the electrons and the ferrous ions must be removed. Otherwise, the reverse reaction becomes significant and equilibrium is established. The electrons are accepted by the reduction reaction of oxidants present, the most common being dissolved oxygen, 
which absorbs electrons by one of the two following mechanisms :

$$
\frac{1}{2} O_{2}(\text { dissolved })+2 e^{-}=o^{2-}(a q)
$$

or

$$
\frac{1}{2} \mathrm{O}_{2} \text { (dissolved) }+\mathrm{H}_{2} \mathrm{O}(\mathrm{l})+2 \mathrm{e}^{-}=2 \mathrm{OH}^{-}(\mathrm{aq})
$$

The ferrous ions either dissolve in the surrounding water and are removed, or combine with the oxygen or hydroxyl ions available to form a surface deposit according to Reaction (4) or (5), as shown below. The location of the oxidation reaction is called the anode; that of the reduction reaction is called the cathode. Thus, the oxidation reaction is the anode reaction, and the reduction reaction being the cathode reaction. The anode and cathode reactions may proceed adjacently, or they may be separated by a considerable distance, provided they have a low-resistance electrical connection for electron transfer. However, the two reactions must occur simultaneously if corrosion is to proceed. Neither can occur alone. Thus, the overall reaction of iron corroding in an aqueous solution can be represented by one of the following two reactions:

$$
\begin{aligned}
& \mathrm{Fe}(\mathrm{s})+\frac{1}{2} \mathrm{O}_{2} \text { (dissolved) }=\mathrm{FeO}(\mathrm{s}) \\
& \mathrm{Fe}(\mathrm{s})+\frac{1}{2} \mathrm{O}_{2} \text { (dissolved) }+\mathrm{H}_{2} \mathrm{O}(1)=\mathrm{Fe}(\mathrm{OH})_{2}(\mathrm{~s})
\end{aligned}
$$


Similarly, the corrosion of zinc in aqueous solutions can be represented by one of the following two reactions:

$$
\begin{aligned}
& \mathrm{Zn}(\mathrm{s})+\frac{1}{2} \mathrm{O}_{2} \text { (dissolved) }=\mathrm{ZnO}(\mathrm{s}) . \\
& \mathrm{Zn}(\mathrm{s})+\frac{1}{2} \mathrm{O}_{2} \text { (dissolved) }+\mathrm{H}_{2} \mathrm{O}(1)=\mathrm{Zn}(\mathrm{OH})_{2}(\mathrm{~s})
\end{aligned}
$$

However, the tendency of zinc to corrode is different from that of iron since the Gibbs free energy change involved when zinc corrodes is different from that of iron. The more negative the value of the free energy change, $\Delta G$, for a corrosion reaction, the greater is the tendency for that particular reaction to occur. However, this is not a measure of the rate of the corrosion reaction. A larger negative $\Delta G$ may or may not be accompanied by a high corrosion rate, but when $\Delta G$ is positive it is for sure that the reaction will not proceed at all under the particular condition considered.

\section{2-2 Definitions of Electrochemical Potential of zinc and Iron}

In view of electrochemical science, the tendency for a metal, to corrode can be also expressed in terms of the electrochemical potential of a corrosion cell, which is a combination of an electrolyte and two electrodes electrically connected with each other. Only differences in electrochemical potential between two electrodes can be measured 
experimentally(10) . To determine directly a single electrode potential, it is necessary to couple the electrode with another whose electrochemical potential is defined as zero. Conventionally, the electrochemical potential of the normal hydrogen electrode (NHE) at $25^{\circ} \mathrm{C}$ is defined as zero. Therefore, the electrochemical potential, V, of zinc, or the electromotive force of zinc, can be defined as the voltage reading obtained when coupled with a NHE at $25^{\circ} \mathrm{C}$. The pertinent reaction here is:

$$
\mathrm{Zn}^{2+}(\mathrm{aq})+2 \mathrm{e}^{-}=\mathrm{Zn}(\mathrm{s})
$$

The electrochemical potential for iron is therefore also defined as the voltage reading obtained when coupled with a NHE at $25^{\circ} \mathrm{C}$. The reaction in this case is:

$$
\mathrm{Fe}^{2+}(\mathrm{aq})+2 \mathrm{e}^{-}=\mathrm{Ee}(\mathrm{s})
$$

In this study, the convention prompted by the International Union of Pure and Applied Chemistry is adhered to, and therefore the symbol " $V$ " is used to refer to the reduction potential of a metal. Since the anode reaction of a corrosion cell is an oxidation reaction, its electrochemical potential should be the oxidation potential, i.e., the negative of the reduction potential. Therefore, the cell potential, E, is 
defined as the algebraic difference of reduction potentials of the cathode and the anode, i.e.,

$$
E=v_{c}-v_{a}
$$

where $V_{c}$ is the (reduction) electrochemical potential of the cathode, and $\mathrm{V}_{\mathrm{a}}$ is the (reduction) electrochemical potential of the anode. The relationship between $\Delta G$ and $E$ which correspond to the same reaction is defined by the following equation :

$$
\Delta \mathrm{G}=-\mathrm{nFE}
$$

where $\mathrm{n}$ is the number of electrons participating in the reaction, and $F$ is the Faraday constant. Substituting Eq. (10) into $\mathrm{Eq} \cdot(11)$ gives

$$
\Delta G=n F\left(V_{a}-V_{c}\right)
$$

For a metal to corrode, it must act as an anode, since oxidation occurs at the anode. Therefore, the greater the value of $V_{a}$ for a metal, the greater would the $\Delta \mathrm{G}$ for the corrosion reaction of the metal be, and vice versa. Thus, the metal with a more positive (reduction) electrochemical potential has less tendency to corrode. 
Table 1 lists the standard electrochemical potentials, $\mathrm{V}^{0}$, of some electrode reactions at $25^{\circ} \mathrm{C}$. As can be seen from this table, zinc has a more negative standard electrochemical potential than iron, and therefore is anodic to iron under standard conditions at $25^{\circ} \mathrm{C}$.

An electrochemical potential difference exists between two dissimilar metals when they are immersed in a corrosive or conductive solution and placed in contact, or otherwise electrically connected. Oxidation of the more anodic metal (anode) produces the electrons which will move to the less anodic metal (cathode), through the electric connection between these two metals, to lower the free energy of the system as a whole. The movement of electrons to the cathode occurs because of the potential difference between these two metals. Electron accumulation at the cathode will continue until the potential difference between the anode and cathode is neutralized. It is this electron accumulation which protects the cathode, with the result of the anode being oxidized and thus sacrificed. This is the mechanism for galvanic protection. In the case of galvanized steel, this is one of the two mechanisms by which the steel is protected from corrosion, with zinc serving as the sacrificial anode. Another mechanism for protection of the steel is to isolate it from the corrosive medium. This is discussed in greater detail in next section. 
Table 1. Standard electrode potentials" $\mathrm{V}^{0}$ of some electrode reactions at $25^{\circ} \mathrm{C}$ (after Ref. 11).

\begin{tabular}{|c|c|c|c|}
\hline Electrode reaction & \multicolumn{2}{|c|}{$v^{0}($ volt $)$} & \\
\hline $\mathrm{Li}^{+}+\mathrm{e}^{-}=\mathrm{Li}$ & -3.01 & Anodic & \\
\hline $\mathrm{Na}^{+}+e^{-}=\mathrm{Na}$ & -2.71 & A & \\
\hline $\mathrm{Mg}^{2+}+2 \mathrm{e}^{-}=\mathrm{Mg}$ & -2.38 & & \\
\hline $\mathrm{Mn}^{2+}+2 \mathrm{e}^{-}=\mathrm{Mn}$ & -1.05 & & \\
\hline $\mathrm{Zn}^{2+}+2 \mathrm{e}^{-}=\mathrm{Zn}$ & -0.76 & & \\
\hline $\mathrm{Fe}^{2+}+2 \mathrm{e}^{-}=\mathrm{Fe}$ & -0.44 & & \\
\hline $\mathrm{Ni}^{2+}+2 \mathrm{e}^{-}=\mathrm{Ni}$ & -0.23 & & \\
\hline $\mathrm{Sn}^{2+}+2 \mathrm{e}^{-}=\mathrm{Sn}$ & -0.14 & & \\
\hline $\mathrm{Pb}^{2+}+2 \mathrm{e}^{-}=\mathrm{Pb}$ & -0.13 & & \\
\hline $2 \mathrm{H}^{+}+2 \mathrm{e}^{-}=\mathrm{H}_{2}$ & 0.00 & & \\
\hline $\mathrm{Cu}^{2+}+2 \mathrm{e}^{-}=\mathrm{Cu}$ & 0.34 & $\|$ & . \\
\hline $\mathrm{O}_{2}+2 \mathrm{H}_{2} \mathrm{O}+4 \mathrm{e}^{-}=4 \mathrm{OH}^{-}$ & 0.40 & & \\
\hline $\mathrm{Cu}^{+}+\mathrm{e}^{-}=\mathrm{Cu}$ & 0.52 & & \\
\hline $\mathrm{rg}^{2+}+2 \mathrm{e}^{-}=\mathrm{Hg}$ & 0.80 & & \\
\hline $\mathrm{Ag}^{+}+\mathrm{e}^{-}=\mathrm{Ag}$ & 0.80 & & \\
\hline $\mathrm{Ir}^{3+}+3 \mathrm{e}^{-}=\mathrm{Ir}$ & 1.00 & 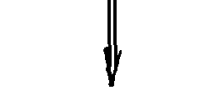 & \\
\hline $\mathrm{O}_{2}+4 \mathrm{H}^{+}+4 \mathrm{e}^{-}=2 \mathrm{H}_{2} \mathrm{O}$ & 1.23 & Cathodic & \\
\hline
\end{tabular}

* The standard electrochemical potential of a metal is defined as the equilibrium potential of the metal in contact with its ions at a concentration equal to unit activity. 


\section{2-3 Necessary Conditions for Corrosion to Occur}

Since corrosion attack of metals takes place in the form of ionization and subsequent dissolution, in order for a metal M to corrode, the following oxidation reaction must occur:

$$
M(s)=M^{n^{+}}(a q)+n e^{-}
$$

In order for the occurrence of this reaction to be possible, the appropriate driving force, G, must be associated with it. Further, both the metallic ions and the electrons must also be removed. The routes for removing them are termed the ion path and electron path, respectively. Therefore, the conditions necessary for a corrosion reaction to proceed are the existence of: (1) the requisite driving force, (2) the ion path, and (3) the electron path. These three necissary conditions can be expressed in the form of a "Corrosion Triangle," as shown in Figure $1^{*}$. In order for corrosion to proceed, this triangle must be "closed." If any one of the sides, or components, is interrupted or broken, the corrosion process is halted. However, halting of the corrosion process does not necessarily mean that all the three conditions are reversed or interrupted. For example, in the case of aluminum, which is a reactive metal, a stable aluminum oxide * The author would like to credit Dr. R. N. Anderson, for
orjginating this concept. 


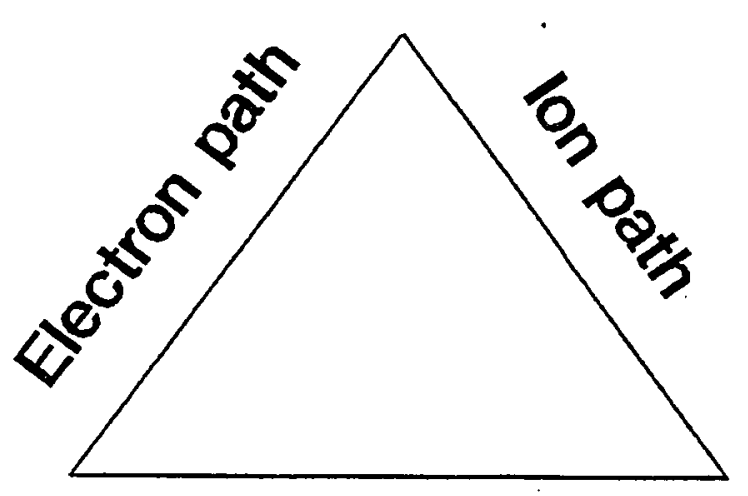

Driving force

Eigure 1. Corrosion triangle showing the three components necessary for corrosion to occur. 
coating develops very rapidly, thus protecting it from further atmospheric corrosion. The aluminum oxide coating interrupts the ion path for the combination of aluminum ions and oxygen ions. However, the driving force for aluminum to corrode in atmosphere still continues to exist, regardless of whether or not the corrosion reaction is proceeding.

\section{2-4 Corrosion Protection of Steel}

Corrosion of iron in an aqueous environment will stop if (1) the electrical connection (or electron path) is interrupted; (2) the oxidation product, $\mathrm{Fe}^{2+}$, is saturated, i.e., the ion path for $\mathrm{Ee}^{2+}$ and $\mathrm{OH}^{-}$(or $\mathrm{O}^{2-}$ ) combination is interrupted; or (3) oxidation of the iron is replaced by oxidation of another metal, which is anodic to iron.

zinc coatings of the galvanized steel act in two ways to protect the steel from corrosion. First, they serve to keep the electrolytes away from the steel, thus interrupting the ion path. Next, when steel does become exposed to the electrolyte, zinc acts as the sacrificial anode since zinc is anodic to steel.

\section{2-5 Polarization Effect of an Electrode}

The foregoing sections of this chapter dealt with the standard electrochemical potential, which is in actuality the equilibrium potential under a condition of unit activity. 
The equilibrium state requires the electrochemical potential of an electrode to be measured under open-circuit conditions, i.e., the net current flowing through the electrode should be zero.

An electrode is no longer at equilibrium when a net current flows to or from its surface. The measured potential of such an electrode is altered to an extent that depends on the magnitude of the external current. This phenomenon is called polarization, which affects the value of the measured potential of the electrode. The polarization effect and the non-equilibrium potential of an electrode are discussed in the following paragraphs.

Every electrode reaction, either an oxidation reaction or reduction reaction, involves a definite number of electrons. The amount of a reactant that transforms to a product corresponds to a fixed number of electron production or consumption. Accordingly, the rate of a reactant that transforms to a product, i.e., reaction rate, corresponds to the rate of electron production or consumption. For a electrochemical reaction to proceed, electrons must flow from the place where they are produced (anode) to the place where they are consumed (cathode). Since current is an expression of the rate of electron flow, the rate of an electrochemical reaction can be represented by the current which flows between the anode and the cathode of the electrochemical reaction. 
Consider the reduction reaction of a species 0 at an electrode:

$$
0+n e^{-}=R
$$

When the reduction reaction occurs; $i . e$. , the electrode acts as a cathode, the reaction rate of this reduction can be expressed by a cathodic current, $i_{c}$. On the other hand, when the oxidation reaction occurs, i.e., the electrode acts as an anode, the reaction rate of this oxidation can be expressed by an anodic current, $i_{a}$. Conventionally, $i_{c}$ is defined as a positive value. Since the direction of electron flow for $i_{a}$ is opposite to that of $i_{c}, i_{a}$ is negative. At equilibrium, the reaction rates for reduction and oxidation are equal, i.e., $i_{c}=-i_{a}$, thus the net current $i$, which is defined as the algebraic sum of $i_{c}$ and $i_{a}$, is zero. The equilibrium potential, $E_{e q}$, is the electrochemical potential of the electrode. If the net current $i$ is not zero, then the potential of the electrode is not in an equilibrium state, and the electrode potential, E, at this condition will be different from $E_{\text {eg }}$. In this case, the electrode is said to be polarized. Polarization is defined as the extent of potential change caused by the net current to or from an electrode. The magnitude of polarization is measured in terms of overvoltage, which is a measure of polarization with 
respect to the equilibrium potential of an electrode. That is, overvoltage is a magnitude by which the potential of an electrode, E, would shift from its equilibrium potential, $E_{\text {eq' }}$, when there is a net current flowing through the electrode.

The principles governing the relationship between the electrode potential and the current flowing through an electrode have been extensively discussed by Bockris and Reddy ${ }^{(12)}$, Unlig ${ }^{(13)}$, and Fontana ${ }^{(14)}$. A brief discussion is given in the following sections.

\section{2-5-1 Activation Polarization}

Again, consider the reduction reaction of a species 0 at an electrode:

$$
0+n e^{-}=R
$$

If the activation energy requirement of the Reaction (14) is large or currents are kept so low that the concentrations of $O$ and $R$ in the electrolyte at the electrode surface do not differ appreciably from the bulk values, then the ButlerVolmer equation ${ }^{(15)}$ applies, i.e.,

$$
i=i_{0}\left[e^{(-\alpha n f \phi)}-e^{(1-\alpha) n f \phi}\right]
$$

where $i$ is the net current which flows through the electrode; 
$i_{0}$ is the exchange current which is equal in magnitude. to either cathodic or anodic current at equilibrium;

$\alpha$ is the transfer coefficient and can usually be approximated by 0.5 in the absence of actual measurements ${ }^{(16)}$;

$f$ is defined as $F / R T$ where $F, R$, and $T$ are the Faraday constant, the gas constant, and the temperature in degrees of Kelvin, respectively;

$\phi$ is the overvoltage due to activation polarization, and is defined as $E-E_{\text {eq }}$.

When the $\phi$ of an electrode is large, either positive or negative, only one item in the term "[ $\left.e^{(-\alpha n f \phi)}-e^{(1-\alpha) n f \phi}\right] "$, appearing in the right hand side of Eq.(15), is important. That is,

$$
\begin{aligned}
& \text { when } \phi \ll 0,\left[e^{(-\alpha n f \phi)}-e^{(1-\alpha) n f \phi}\right] \approx e^{(-\alpha n f \phi)} \\
& \text { when } \phi>0,\left[e^{(-\alpha n f \phi)}-e^{(1-\alpha) n f \phi}\right] \approx-e^{(1-\alpha) n f \phi}
\end{aligned}
$$

Therefore, at large negative overvoltages, Eq.(15) reduces to

$$
E=\beta_{c} \log \left(\left|i / i_{o}\right|\right)+E_{e q}
$$

where $i$ is the net current, and is equal approximately to the cathodic current in this condition, $i . e ., i \approx i_{c}$,

$B_{C}$ is called the cathodic Tafel coefficient or beta slope, and equals to $-2.303 R T / \alpha n F$. Similarly, at large 
positive overvoltages, Eq.(15) reduces to

$$
E=\beta_{a} \log \left(\left|i / i_{0}\right|\right)+E_{\text {eq }}
$$

where $i$ is the net current and is equal approximately to the anodic current in this condition, $i . e ., i \approx i_{a}$,

$B_{2}$ is called the anodic Tafel coefficient or beta slope and equals to $[2.303 \mathrm{RT} /(1-\alpha) \mathrm{nF}]$. Plotting the electrode potential, E, vs. the logarithm of the net current $i$ gives the activation polarization curve of an electrode, as shown in Eigure 2. From the definitions of the cathodic and anodic Tafel coefficients, these two are equal in magnitude when $\alpha$ is $1 / 2$.

Beside the activation polarization, there is another kind of polarization, i.e., concentration polarization which is discussed below.

\section{2-5-2 Concentration Polarization}

Again, consider the reduction reaction of a species 0 at an electrode:

$$
0+n e^{-}=R
$$

At very high reduction rates, the region adjacent to the electrode surface will become depleted of 0 . If the reduction 


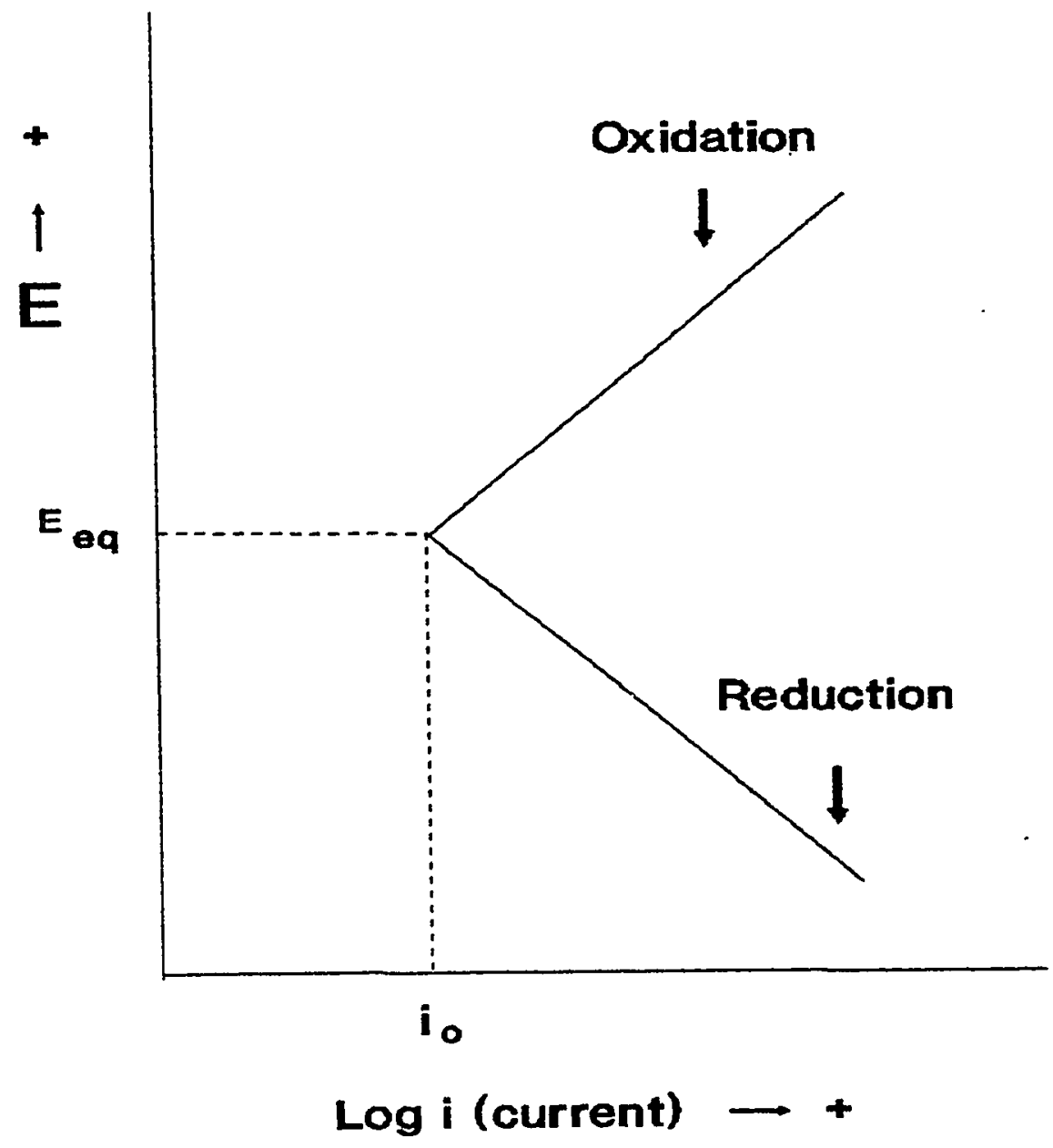

Eigure 2. Schematic representation of the potential $E$ of an electrode under activation polarization. 
rate is increased further, a limiting reaction rate will be reached that is determined by the diffusion rate of 0 to the electrode surface. This limiting reaction rate can be expressed by a limiting diffusion current, $i_{L}$. Limiting diffusion current is usually only significant during a reduction reaction, i.e., a cathode reaction, and is usually negligible during the metal-oxidation reaction, since there is an almost unlimited supply of metal atoms for dissolution ${ }^{(17)}$.

Since $i_{L}$ is limited by the diffusion rate of ions or dissolved atoms in the electrolyte, it is expected that $i_{L}$ would be increased when the temperature is raised, if the concentration of the ions or dissolved atoms in the electrolyte is independent of the temperature.

If an electrode in which there is no activation polarization is considered, then the equation for concentration polarization ${ }^{(17)}$ is

$$
\phi_{c}=(2.303 \mathrm{RT} / \mathrm{nF}) \times \log \left(1-i / i_{L}\right)
$$

where $\phi_{c}$ is the overvoltage due to concentration polarization. Examination of Eq.(20) indicates that when the net reduction current equals to the limiting diffusion current, overvoltage is equal to negative infinity. 


\section{2-5-3 Combined Polarization}

The total polarization of an electrode is the sum of the contributions of activation and concentration polarizations, i.e.,

$$
\phi_{t}=\phi_{a}+\phi_{c}
$$

where $\phi_{t}$ is the total overvoltage,

$\phi_{a}$ is the overvoltage due to activation polarization,

$\phi_{C}$ is the overvoltage due to concentration polarization.

For metal dissolution, concentration is not a factor as discussed above, and thus the equation fo: the kinetics of anodic dissolution of a metal is given by $\mathrm{Ec}_{i} \cdot(19)$, i.e.,

$$
E=B_{a} \log \left(\left|i / i_{0}\right|\right)+E_{e q}
$$

On the contrary, during the reduction process such as hydrogen evolution or oxygen reduction, concentration polarization becomes important as the reduction rate approaches the limiting diffusion current, and thus the equation for the kinetics of a cathodic reduction is given by combining Eqs. (18) and (20):

$$
E=\beta_{C} \log \left(\left|i / i_{0}\right|\right)+2.303(R T / n E) \times \log \left(1-i / i_{L}\right)+E_{e q}(22)
$$


Equation (22) is graphically illustrated in Eigure 3. As can be seen from this figure, concentration polarization becomes important only when net current approaches $i_{L}$. That is, when $i \ll i_{L}$, Eq. (22) reduces to Eq. (18), i.e.,

$$
E=B_{c} \log \left(\left|i / i_{o}\right|\right)+E_{\text {eq }}
$$

Therefore, only the linear part of polarization curve in this figure needs to be considered when the net current does not approach $i_{\mathrm{L}}$.

The polarization curve for a single oxidation-reduction reaction is one of the fundamental theories for graphically determining, as discussed below, the corrosion potential of a metal. Another is the mixed-potential theory.

\section{2-6 Mixed-Potential Theory}

A mixed electrode is an electrode or metal sampie that is in contact with two or more oxidation-reduction systems. Due to the charge conservation, the total rate of oxidation must equal to the total rate of reduction, and this is called the mixed-potential theory.

Consider a metal $M$ immersed in an electrolytic solution of high conductivity, i.e., negligible potential drop due to current flow. When the metal is corroded, there must also be a reduction reaction, i.e., cathodic reaction, to consume the 


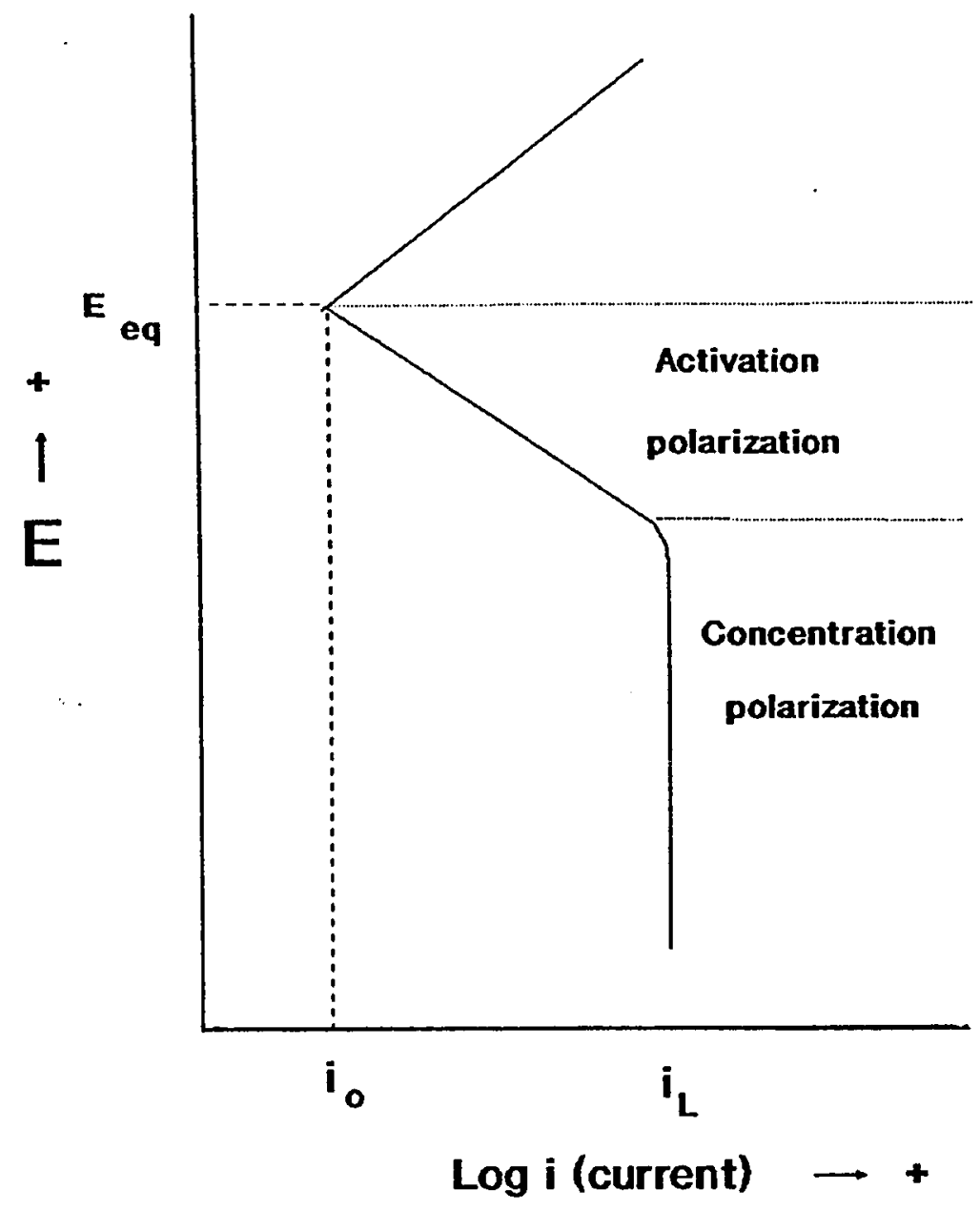

Eigure 3. Schematic representation of the potential $E$ of an electrode under activation and concentration polarizations (after Ref. 18). 
electrons produced by the metal oxidation occurring on the metal surface simultaneously. Assume the anode and cathode reactions are as follows:

$\begin{array}{ll}\text { Anode } & \mathrm{M}=\mathrm{M}^{\mathrm{n}^{+}}+\mathrm{n} \mathrm{e}^{-} \\ \text {Cathode } & \mathrm{R}^{\mathrm{Z}^{+}}+\mathrm{z} \mathrm{e}^{-}=\mathrm{R}\end{array}$

If the metal $M$ in equilibrium with its ions is considered, it would be represented by an equilibrium potential, $\mathbf{E}_{M, e q}$, and an exchange current, $i_{0 a}$, corresponding to the anode reaction. Likewise, if the cathode reaction under equilibrium condition is considered, then this particular equilibrium state would be represented by the equilibrium potential, $\mathrm{E}_{\mathrm{c} \text {,eq }}$, and an exchange current, $i_{c c}$, for the cathode reaction occurring at the metal M surface. However, when anode and cathode reactions occur simultaneously, i.e., polarization occurs, the metal electrode cannot remain at either of these two equilibrium potentials but must lie at some other potential. Since metal is an excellent electrical conductor, its entire surface must be at a constant potential at which the mixed-electrode theory is satisfied, i.e., the rate of oxidation reaction must equal to the rate of reduction reaction.

$$
\text { Since current is an expression of reaction rate, as }
$$
discussed in section 2-5, the mixed-potential theory can be 
restated as follows: the magnitude of the anodic current must be equal to that of the cathodic current.

Figure 4 illustrates graphically the mixed-potential of a metal $M$ in a corrosive environment. The only point in polarization curves where the rates of oxidation and reduction are equal is at the intersection represented by a "mixed" or corrosion potential, $E_{\text {corr }}$. Only at this point is charge conservation maintained. The current corresponding to this point is called the corrosion current, $i_{\text {corr }}$, since it represents the rate of the metal corrosion. The difference between the corrosion potential $E_{\text {corr }}$ and the electrode potential at equilibrium $E_{M, e q}$ is clearly shown in this figure.

If more than one reduction reaction can occur at the same time, then the corrosion potential of the metal is the potential at which the total rate of reduction equals the total rate of oxidation, $i . e$. , the total cathodic current of the cathode equals in magnitude to the total anodic current of the anode.

By examining Figure 4, it can be seen that the value of the corrosion potential of a metal can be affected, as discussed below, by the following parameters: the equilibrium potential of the cathode reaction $E_{c, e q}$, and the exchange current of the cathode or the anode, $i_{\text {.e., }} i_{\text {oc }}$ or $i_{o a}$.

If $\mathrm{E}_{\mathrm{C}, \mathrm{eg}}$ is raised, then the corrosion potential increases too. If $i_{o c}$ is increased, due to the increase either in the 


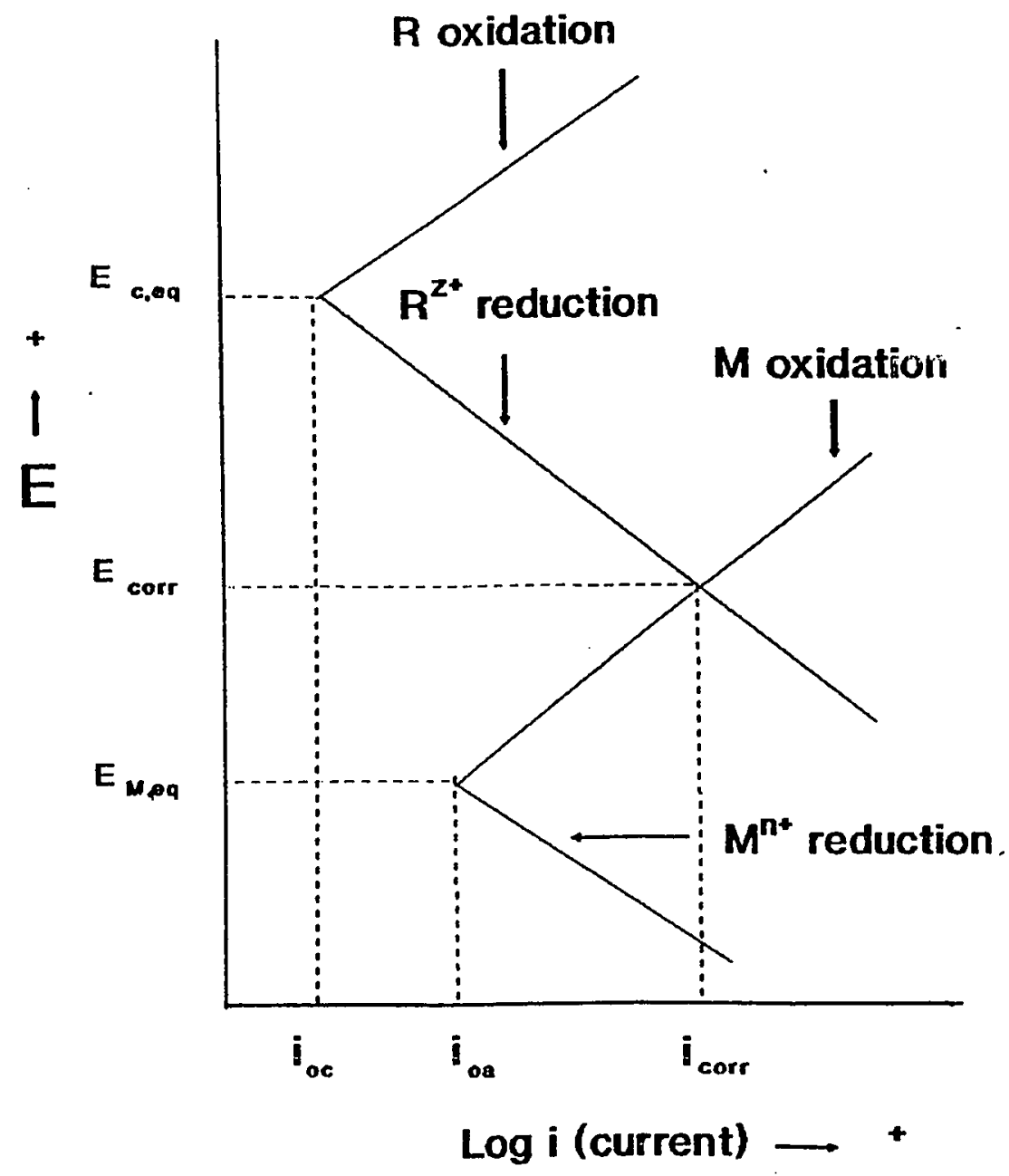

Figure 4. Schematic representation of the electrode behavior of a metal $M$ in a corrosive environment. 
exchange current density of the cathode reaction, $j_{o c}$, or in the area of the cathode, then the corrosion potential increases. On the other hand, the corrosion potential decreases if $i_{0 a}$ is increased, due to the increase either in the exchange current density of the anode reaction, $j_{0 a}$, or in the area of the anode.

From the above discussion, factors that cause the corrosion potential of a metal electrode to be raised can be summarized as follows:

(1). An increase in $\mathrm{E}_{c, e q}$,

(2). An increase in $j_{o c}$ or a decrease in $j_{o a}$, and

(3). An increase in the cathode area, or a decrease in the anode area.

Knowing how these factors affect the value of the corrosion potential of a metal electrode will help to understand the behavior of the metal in a corroding environment.

\section{2-7 Corrosion Potential of Metal in Aqueous Environment}

The cathode reaction of a metal in deaerated water is hydrogen evolution, and that in aerated non-acid water is the combination of hydrogen evolution and oxygen reduction. These are

$$
\begin{aligned}
& 2 \mathrm{H}^{+}(\mathrm{ag})+2 \mathrm{e}^{-}=\mathrm{H}_{2}(\mathrm{~g}) \\
& \mathrm{O}_{2} \text { (dissolved) }+2 \mathrm{H}_{2} \mathrm{O}(1)+4 \mathrm{e}^{-}=4 \mathrm{OH}^{-}(\mathrm{aq})
\end{aligned}
$$


The standard electrochemical potential of Reaction (26), at $25^{\circ} \mathrm{C}$, is 0.401 volt, which is much higher than that of hydrogen evolution, and thus resulting in the higher cathodic equilibrium potential in aerated water than in deaerated water. Therefore, the corrosion potential of a metal would generally be larger in aerated water than in deaerated water.

Table 2 lists the Tafel coefficients and exchange current densities for some electrode systems in aqueous solutions at $25^{\circ} \mathrm{C}$. As can be seen from this table, $j_{0}$ of the hydrogen evolution on zinc electrode is much less than that of the $\mathrm{Zn}^{2+} \mathrm{Zn}$ system. Besides, $j_{0}$ of the oxygen reduction on iron electrode is also much less than that of the hydrogen evolution on the same electrode. By plotting the polarization curve of a metal electrode and that for the hydrogen evolution as well as the oxygen reduction on the metal electrode, the corrosion potential of this metal in an aqueous environment can be determined graphically according to the mixed-potential theory, as discussed in section 2-6. In the case of zinc and iron in aqueous environment, the corrosion potential will be discussed in detail in Chapter 7.

From the above description, the corrosion potential of a metal is strongly dependent on the species present in its surrounding, i.e., environment dependent. However, the standard electrochemical potential of a metal at a fixed 
Table 2. Standard electrochemical potentials, Tafel coefficients $B$, and exchange current densities $j$ for some electrode systems in aqueous solutions at $25^{\circ} \mathrm{C}$ (after Ref. 19).

\begin{tabular}{|c|c|c|c|c|}
\hline System & $\begin{array}{c}\text { Metal } \\
\text { Electrode }\end{array}$ & $\begin{array}{c}v^{0} \\
\text { volt }\end{array}$ & $\begin{array}{c}B^{*} \\
\text { volt }\end{array}$ & $\underset{\mathrm{A}}{\mathrm{j}} / \mathrm{m}^{2}$ \\
\hline $\mathrm{Fe}^{2+} \mid \mathrm{Ee}$ & $\mathrm{Fe}$ & -0.440 & $0.05-0.08$ & $10^{-5}$ to $10^{-4}$ \\
\hline $\mathrm{Zn}^{2+} \mid \mathrm{Zn}$ & $\mathrm{Zn}$ & -0.763 & $0.03-0.06$ & $10^{-3}$ to $10^{-1}$ \\
\hline $\mathrm{H}^{+} \mid \mathrm{H}_{2}$ & Pt & 0.000 & $\approx 0.12$ & $10^{2}$ \\
\hline $\mathrm{H}^{+} \mid \mathrm{H}_{2}$ & $\mathrm{Ee}$ & 0.000 & $\approx 0.12$ & $10^{-3}$ to $10^{-2}$ \\
\hline $\mathrm{H}^{+} \mid \mathrm{H}_{2}$ & $\mathrm{Zn}$ & 0.000 & $\approx 0.12$ & $10^{-7}$ \\
\hline $\mathrm{O}_{2} / \mathrm{OH}^{-}$ & Pt & 0.401 & $0.10-0.15$ & $10^{-6}$ \\
\hline $\mathrm{O}_{2} \mathrm{OH}^{-}$ & $\mathrm{Fe}$ & 0.401 & $>0.12$ & $\approx 10^{-10}$ \\
\hline
\end{tabular}

* Magnitudes of anodic and cathodic Tafel coefficients are equal when transfer number is $1 / 2$. 
temperature is a constant, and is independent of its environment. Therefore, these two potentials are different and should be clearly distinguished.

Besides illustrating the polarization effect and the corrosion potential of a metal electrode, the discussion in this chapter has focused on developing the conditions necessary for a corrosion reaction to occur, and the mechanisms via which the steel in galvanized steel pipes can be expected to be protected by the zinc layer. There have, however, been several reports of instances where the zinc layer was considered inadequate for protecting the underlying steel from corroding. These reports, and their findings, are discussed in the next chapter. 
Chapter 3. EAILURE OE ZINC TO PROTECT STEEL

Failure of the zinc coating to provide the underlying steel with galvanic protection has been reported in some cases $^{(1-9)}$, and are reviewed in this chapter. For example, the protective effect of the $\mathrm{Zn}-\mathrm{Fe}$ alloy layer on iron was studied by Britton ${ }^{(1)}$. He found that at room temperature these alloys offered only temporary protection to the iron and became cathodic to the iron when the corrosion of the iron commenced, and concluded that "the alloy layer is of no use in providing electrochemical protection to iron, though zinc appears to be potentially of great value in this respect." The rapid failure of galvanized steel was explained by Britton on the basis of failure of the water to lay down a calcareous film on the bared steel. The above explanation accords with the view stated by Baylis ${ }^{(2)}$ that the function of a zinc coating was to afford temporary protection to the underlying iron or steel while the more permanent protection was the formation of a calcium carbonate $\left(\mathrm{CaCO}_{3}\right)$ film.

While the above investigators conducted general studies pertaining to the performance of zinc coatings in protecting steel, other investigators ${ }^{(3-9)}$ have conducted more specific studies aimed at identifying the cause of this phenomenon. The specific causes studied were (1) the effect of the hot water temperature, (2) the effect of the presence or absence 
of dissolved oxygen in the water, and (3) the effect of the chemical composition of the water, $i . e .$, the effect of solute in the water.

\section{3-1 Effect of Temperature}

By measuring the current flowing between a galvanized steel pipe and an iron rod, Schikorr ${ }^{(3)}$ reported that zinc, in Berlin water containing Cao impurity, actually could become cathodic to iron after a short exposure above $60^{\circ} \mathrm{C}$. He further identified experimentally that a protective film, $\mathrm{CaCO}_{3}$, was formed on the zinc surface of the pipe, and not on the surface of the iron rod. The ennoblement of zinc potential at temperatures above $60^{\circ} \mathrm{C}$ was attributed to a very compact film or layer of zinc corrosion product which is produced at these elevated temperatures.

It appears that the galvanic protection of iron by zinc in hot water is dependent on the temperature of the water, and on the characteristic of corrosion products formed on the zinc surface. The ennoblement of zinc seems to occur if the corrosion product is compact and adherent, which was the case in the above investigation.

Roters and Eisenstecken ${ }^{(4)}$ found that pure zinc, galvanized steel, or Zn-Fe alloys could become cathodic to iron, when they were coupled with a piece of iron and were immersed in distilled water. This occurred after 2 to 4 weeks 
exposure even at room temperature, particularly if carbonates were added to the solution. They explained the reversal of polarity by attributing it to the changes in the potential of the zinc, while the potential of iron remained practically constant throughout the tests.

Kenworthy and Smith ${ }^{(5)}$ investigated the effects of temperature and free carbon dioxide content on the galvanic protection of iron by zinc. They found that in hot hard waters, zinc failed to give any appreciable electrochemical protection to the exposed steel. Moreover, corrosion of the zinc in galvanized steel samples was generally the worst in the waters having the highest carbon dioxide content, and the least in the waters free from carbon dioxide. Therefore, they emphasized the need for continuous zinc coatings.

In a 15-year service test on cold and hot lime-treated Baltimore waters, Bonilla ${ }^{(6)}$ reported that galvanized steel pipe pitted less deeply than black wrought iron pipe in cold waters, but pitted more deeply in hot waters. Since zinc remained on the tested samples, he concluded that the galvanizing was cathodic to the pits in the galvanized pipes tested in hot waters.

From the above descriptions, it seems that the zinc coatings, at elevated temperatures, not only did not protect the bared steels from corrosion, but actually even accelerated the corrosion of steels in some cases. The above 
investigations lead one to the conclusion that failure of the galvanic protection mechanism occurs when the following conditions exist simultaneously:

(1) elevated temperatures, i.e., $60^{\circ} \mathrm{C}$ or above,

(2) formation of corrosion products on the surface of zinc.

The failure of zinc coating in galvanized steel to protect the underlying steel at elevated temperatures was attributed, by the previous investigators, to the ennoblement of zinc. This explanation may or may not be true since the zinc potential was measured when its surface was covered by corrosion products, and therefore cannot be treated as the electrochemical potential of zinc. Whether the electrochemical potential of zinc itself was ennobled was not established in these investigations.

\section{3-2 Effect of Dissolved Oxygen}

By measuring the short circuit current of a zinc-steel couple and the single electrode potentials of zinc and steel samples, Gilbert ${ }^{(7)}$ reported that in the absence of oxygen, zinc remained anodic to steel at temperatures up to $85^{\circ} \mathrm{C}$. In aerated solutions he found that a temperature of over $60^{\circ} \mathrm{C}$ was necessary for zinc to become cathodic to iron. This reversal was attributed to the ennoblement of zinc, and Gilbert referred to this phenomenon as a "potential reversal" between zinc and iron. On cooling below $60^{\circ} \mathrm{C}$ the zinc was found to 
become anodic to the steel again. Gilbert attributed the noble zinc potentials observed over $60^{\circ} \mathrm{C}$ to the formation of Zno at these temperatures and the anodic potentials at lower temperatures to the formation of $\mathrm{Zn}(\mathrm{OH})_{2}$. His investigation showed that both the presence of oxygen and elevated temperatures are required for the occurrence of potential reversal between zinc and iron, if it indeed does occur.

\section{3-3 Effect of Water Composition}

Gilbert also investigated the effects of $\mathrm{NaHCO}_{3}, \mathrm{KCl}$, and $\mathrm{K}_{2} \mathrm{SO}_{4}$ on the potential reversal between zinc and iron. He found that addition of $\mathrm{NaHCO}_{3}$ in the electrolyte favored the occurrence of the reversal, while that of $\mathrm{KCl}$ and $\mathrm{K}_{2} \mathrm{SO}_{4}$ inhibited this reversal. Hoxeng and Prutton ${ }^{(8)}$ concluded that both temperature and electrolyte composition are important in determining the behavior of zinc-steel couples. They measured the short-circuit current of zinc-steel couples, and the single electrode potentials of zinc and steel samples, as a function of time -- maximum $\vec{u}$ hours, in several different electrolytic solutions. These solutions were produced by adding different weight percentages of sodium salts (chloride, nitrate, sulfate and bicarbonate) to distilled water. The measurements were done at different temperatures ranging from 30 to $80^{\circ} \mathrm{C}$. They reported that the reversal of potential between zinc and steel occurred quickly at both 60 and $70^{\circ} \mathrm{C}$ in 
a solution containing 70-80 $\mathrm{ppm} \mathrm{HCO}_{3}{ }^{-}, 10 \mathrm{ppm} \mathrm{SO}_{4}{ }^{2-}$, and $10 \mathrm{ppm}$ $\mathrm{NO}_{3}{ }^{-}$. Furthermore, they reported that the reversal observed in short circuited zinc-steel couples may be attributed to the potential changes in the zinc on which corrosion products were formed, and that the electrolyte composition must be taken into account in discussing the effect of temperature on the reversal in potentials between zinc and steel. Hoxeng ${ }^{(9)}$, by himself, substantiated their previous results by extending the six-hour laboratory tests up to 96 hours, and by studying the reversal in potential in several other kinds of electrolytic solutions.

The conclusions drawn by Hoxeng and Prutton were similar to those drawn by Gilbert ${ }^{(7)}$. However, Hoxeng and Prutton emphasized that electrolyte composition played a more dominant role than temperature did, since addition of sodium nitrate in some cases lowered the temperature of potential reversal down to $40^{\circ} \mathrm{C}$.

\section{3-4 The "Potential Reversal" Hypothesis}

The above investigations and resulting papers that were published appear to have led to a general acceptance of the concept that zinc and iron go through a "potential reversal" at elevated temperatures, typically $60^{\circ} \mathrm{C}$ or more. It seems that the "potential reversal" between zinc and iron in aerated waters at temperature $60^{\circ} \mathrm{C}$ or above has been generally 
accepted and cited. For example, Myers and obrecht ${ }^{(20)}$ stated that "...in some aerated waters, reversal of polarity between zinc and iron occurs at temperatures above about $60^{\circ} \mathrm{C} . "$ Mihailov and Iovchev ${ }^{(21)}$ also stated that there is a "...reversal of polarity of zinc/steel couples in hot water if oxygen is present." From Royuela ${ }^{(22)}$, the following was found: "The inversion of polarity of the $\mathrm{Zn} / \mathrm{Fe}$ couple must also be kept in mind... The inversion of polarity takes place in soft, low mineralized water and this phenomenon usually occurs in the $60-70^{\circ} \mathrm{C}$ range."

It can be found that observed unsatisfactory performance of galvanized steel pipes in hot water systems is being explained by the occurrence of a "potential reversal" between zinc and iron at elevated temperatures, typically $60^{\circ} \mathrm{C}$ and above. This explanation was forwarded by previous investigators, and appears to have become generally accepted, as a "fact". However, the data reported by previous investigators who have offered this explanation are not definitive. The existing data are such that they apply only to those solutions tested. More importantly, the zinc potential measured by previous investigators is not the electrochemical potential of zinc, but rather the electrode potential of zinc when the zinc was covered by corrosion products. Therefore, the "potential reversal" hypothesis needs to be investigated more critically before being accepted 
as a fact.

\section{3-5 Implications of the Term "Potential Reversal"}

In electrochemistry, the electrochemical potential, $V$, of a metal is a measurement of the ease with which the metal ionizes, or metal ions are reduced, in an electrolytic solution. It is related to its standard value, $V^{0}$, and the activity of its ions, according to the following equation:

$$
V=V^{0}+(2.303 R T / n E) \log a_{i}
$$

where $a_{i}$ is the activity of the metal ions. Under constant temperature conditions, the value of $V$ is not a constant, but is dependent on the value of $a_{i}$, which in turn is dependent on the concentration of the electrolyte. However, $v^{0}$ is constant for constant temperatures. Therefore, in order to determine whether or not metal $A$ is anodic to metal $B$ at a particular temperature, a comparison of the standard electrochemical potentials of A and B is necessary. The word "potential" in the term "potential reversal" must therefore mean the standard electrochemical potential. If the potential reverses, then an electrochemical phenomenon which changes the standard electrochemical potential must occur, rather than an environmentally induced phenomenon, such as a concentration change or the polarization effects caused by the species 
existing in environment.

Failure of galvanic protection of the steel by the zinc on a galvanized steel in hot water systems had been demonstrated experimentally and was attributed to the potential reversal between zinc and iron in hot waters. However, there are several problems with this conclusion. These problems and research objective of this study are presented in the next chapter. 


\section{Chapter 4. PROBLEMS OE "POTENTIAL REVERSAL" HYPOTHESIS AND RESEARCH OBJECTIVE}

The discussion in the previous chapter suggests that zinc becomes cathodic to iron in the presence of dissolved oxygen and elevated temperatures, typically $60^{\circ} \mathrm{C}$ and above. However, problems with this conclusion exist and are discussed in the following:

(1) Though some of previous investigations demonstrated experimentally that the reversal in potential between zinc and steel occurs in waters having certain definite compositions, their results can apply only to those solutions tested, and cannot apply generally to all systems. More important, there was a corrosion product formed on the surface of the zinc when they found the phenomenon of "potential reversal." in this condition, the zinc electrode was not at equilibrium, and thus the potential measured at this time was not a electrochemical potential for the zinc electrode. Therefore, the existing data reported by previous investigators that suggest this conclusion are not definitive.

(2) Although the data of standard electrochemical potentials for zinc and iron in the temperature range of $20^{\circ} \mathrm{C}$ to $80^{\circ} \mathrm{C}$ exist ${ }^{(23)}$ presently, these data may not have been available at the time of previous investigations, and appear not to have been taken into account. 
(3) Investigation of the effect of environmental factors, such as water compositions, is very limited, and requires to be conducted in more detail since it has been found that environmental conditions affect the occurrence of a "potential reversal" between zinc and iron.

(4) The possible effects of the different oxidation states of iron and different compound formations of both zinc and iron, e.g., oxides and hydroxides, are not addressed. These should be taken into account, since the driving forces of oxidation reactions for forming various compounds are different and thus the possibility of the occurrence of a "potential reversal" between $\mathrm{Zn}$ and Fe may be affected.

Therefore, in order to be able to apply the currently accepted notion that zinc and steel go through a potential reversal at some elevated temperatures, more fundamentál work on the temperature dependence of the standard electrochemical potential of each species needs to be undertaken first. The objective of this project is to first determine whether the standard electrochemical potentials of zinc and iron do indeed show a reversal as a function of temperature. If an electrochemical potential reversal is found to occur, the temperature at which this reversal occurs will also be determined.

Subsequent investigations in the applicability of these findings to corrosion in domestic hot water systems will be 
limited to the study of the effect of dissolved oxygen existing in water systems on the temperature at which a "potential reversal" occurs.

This chapter concentrates on the problems of the potential reversal between zinc and iron, and on the objective of this study. The approach to achieve the objective and function of the approach are described in the next chapter. 
Chapter 5. RESEARCH METHODS OF "POTENTIAL REVERSAL"

Both a theoretical and an experimental approach were taken in the research. Existing theory and data were first employed to critically analyze all possible reactions that could occur between $z$ inc and iron in an aqueous environment. The intent of this exercise was to determine if a potential reversal, in the 20 to $80^{\circ} \mathrm{C}$ temperature range, between $\mathrm{zinc}$ and iron could be predicted on theoretical grounds. The theoretical approach is explained in detail in section 5-1. Experiments were then conducted to test the validity of the findings from the theoretical analysis. The experimental methodology is described in section 5-2.

\section{5-1 Thermodynamic Evaluation of Occurrence of Potential}

Reversal

Since the standard electrochemical potential for any reduction-oxidation reaction is related to the standard Gibbs free energy change, $\Delta G^{0}$, comparison of $\Delta G^{0}$ of the corrosion reactions for zinc and iron in aqueous solutions enables us to examine the possibility of the occurrence of a potential reversal between them. Since more than one corrosion product of zinc or iron in aqueous solutions are possibly formed, all of these compounds must be taken into account. Moreover, the $\Delta G^{0}$ of all the oxidation-reduction (redox) reactions between 
zinc and iron must also be considered since they represent the relative stabilities between (elemental), zinc and iron compounds, or (elemental) iron and zinc compounds. A listing of the oxidation reactions of zinc and iron in an aqueous environment is presented in Table 3 . The redox reactions between zinc and iron compounds, in an aqueous environment, are listed in Table 4. The reactions in Table 3 have been formulated on a "per mole of oxygen" basis, so that the number of electrons involved in the reactions are kept constant. This is shown in the following paragraph.

The relationship between the standard Gibbs free energy change, $\Delta G^{0}$, of the corrosion reaction of a metal, $M$, and the standard electromotive potential, $V_{M}^{0}$, of the metal can be expressed according to the following equation:

$$
\Delta G^{0}=-n F\left(V_{C}^{0}-V_{M}^{0}\right)
$$

where $V_{C}^{0}$ is the standard electrochemical potential of the cathode. In order to compare the $v_{M}^{0}$ between zinc and iron, from the values of $\Delta G^{0}$ of the oxidation reactions for these two metals in an aqueous environment, it is necessary to keep both $\mathrm{n}$ and $\mathrm{V}_{\mathrm{c}}^{0}$ constant. The cathode reactions for the corrosion of zinc and iron in aqueous solutions, as discussed in Section 2-1, are one or both of the following two: 
Table 3. Oxidation reactions of zinc and iron in an aqueous environment (basis: one mole of oxygen).

\begin{tabular}{ll} 
Rxn num. & Reaction \\
\hline 1 & $2 \mathrm{Zn}(\mathrm{s})+\mathrm{O}_{2}$ (dissolved) $=2 \mathrm{ZnO}(\mathrm{s})$ \\
2 & $2 \mathrm{Zn}(\mathrm{s})+\mathrm{O}_{2}$ (dissolved) $+2 \mathrm{H}_{2} \mathrm{O}(1)=2 \mathrm{Zn}(\mathrm{OH})_{2}(\mathrm{~s})$ \\
3 & $2 \mathrm{Fe}(\mathrm{s})+\mathrm{O}_{2}$ (dissolved) $=2 \mathrm{FeO}(\mathrm{s})$ \\
4 & $2 \mathrm{Fe}(\mathrm{s})+\mathrm{O}_{2}$ (dissolved) $+2 \mathrm{H}_{2} \mathrm{O}(1)=2 \mathrm{Fe}(\mathrm{OH})_{2}(\mathrm{~s})$ \\
5 & $3 / 2 \mathrm{Fe}(\mathrm{s})+\mathrm{O}_{2}$ (dissolved) $=1 / 2 \mathrm{Fe}_{3} \mathrm{O}_{4}(\mathrm{~s})$ \\
6 & $4 / 3 \mathrm{Fe}(\mathrm{s})+\mathrm{O}_{2}$ (dissolved) $=2 / 3 \mathrm{Fe}_{2} \mathrm{O}_{3}(\mathrm{~s})$ \\
7 & $4 / 3 \mathrm{Fe}(\mathrm{s})+\mathrm{O}_{2}$ (dissolved) $+2 \mathrm{H}_{2} \mathrm{O}(1)=4 / 3 \mathrm{Fe}(\mathrm{OH})_{3}(\mathrm{~s})$ \\
8 & $4 / 3 \mathrm{Fe}(\mathrm{s})+\mathrm{O}_{2}$ (dissolved) $+2 / 3 \mathrm{H}_{2} \mathrm{O}(1)=4 / 3 \mathrm{FeOOH}(\mathrm{s})$ \\
\hline
\end{tabular}


Table 4. Oxidation-reduction reactions of (elemental) zinc and iron compounds in an aqueous environment.

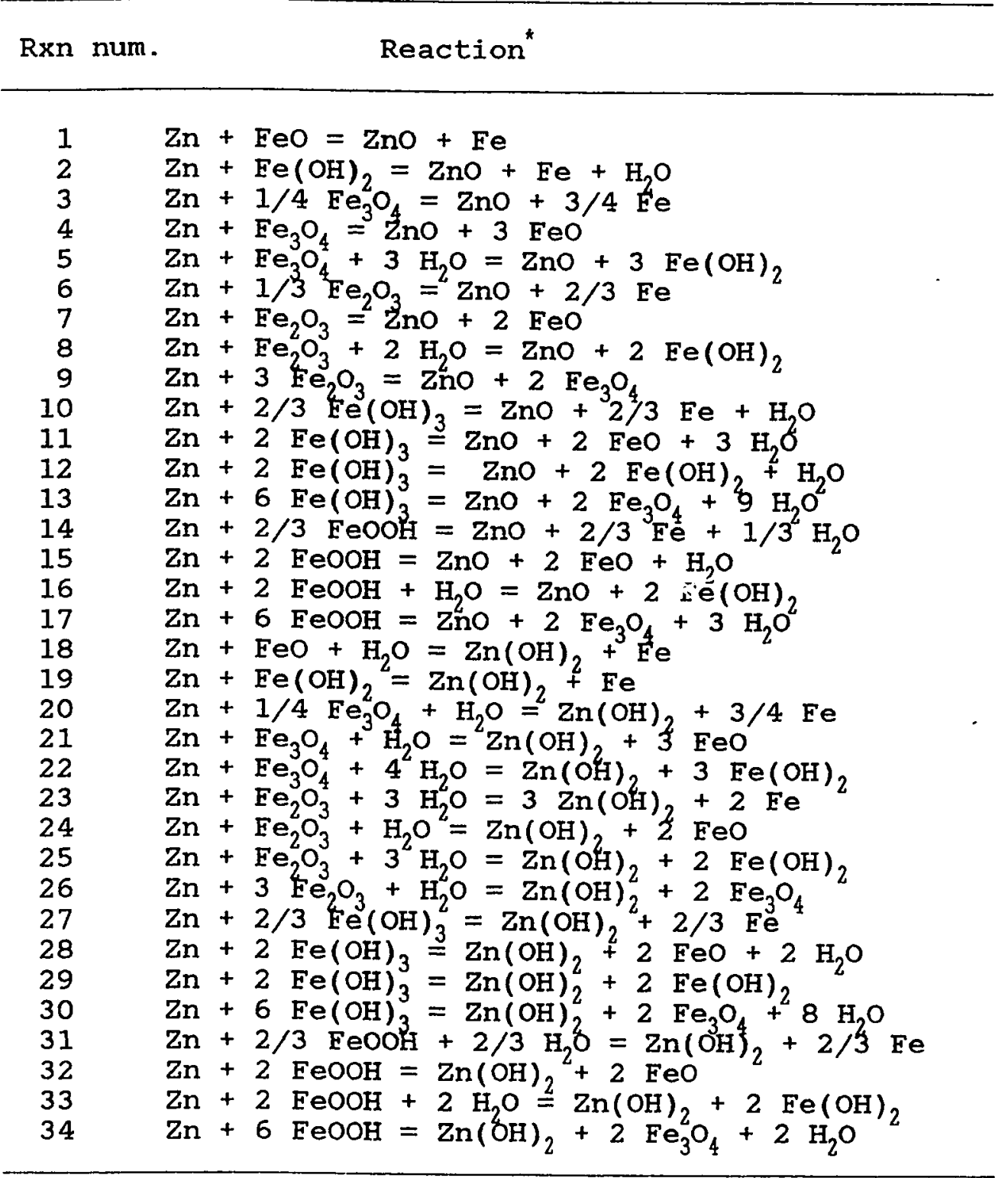

* All species are in solid state except water which is in liquid state. 


$$
\begin{aligned}
& \frac{1}{2} \mathrm{O}_{2} \text { (dissolved) }+2 \mathrm{e}^{-}=\mathrm{O}^{2-}(\mathrm{aq}) \\
& \frac{1}{2} \mathrm{O}_{2} \text { (dissolved) }+\mathrm{H}_{2} \mathrm{O}(\mathrm{l})+2 \mathrm{e}^{-}=2 \mathrm{OH}^{-}(\mathrm{aq})
\end{aligned}
$$

From the Reactions (2) and (3), it can be seen that $n$ stays constant only when the number of the moles of oxygen participating in the reaction is kept constant. Further, when comparing $\Delta G^{0}$ of the oxidation reactions, that for the formation of zinc oxide must be compared with those for iron oxides. The same applies for hydroxides. This is necessary in order to keep $\mathrm{V}_{c}^{0}$ constant. However, either comparison will yield the same result.

\section{5-1-1 Calculation of Standard Free Energy Change of Formation of Compound}

The standard free energy changes of formation of compounds must be known before calculating the standard free energy change of reactions containing these compounds.

The temperature coefficients of the standard heat capacities $\mathrm{C}_{\mathrm{p}}^{0}$, standard enthalpies $\mathrm{H}_{298}^{0}$, and standard entropies $\mathbf{S}_{298}^{0}$ for all the elements and compounds appearing in Table 3, with the exception of zinc hydroxide and goethite $(\mathrm{FeOOH})$, are provided in Appendices $A$ and $B$. The formation reactions of these zinc and iron compounds are provided in Appendix C. The standard free energy change of formation of a compound, at any temperature $\mathrm{T}^{0} \mathrm{~K}$, can be calculated 
according to the following equations:

$$
\begin{aligned}
& \Delta H_{T}^{0}-\Delta H_{298}^{0}=\int_{298}^{P T} \quad C_{p}^{0} d T \\
& \Delta S_{T}^{0}-\Delta S_{298}^{0}=\int_{298}^{T} C_{p}^{0} / T d T \\
& \Delta G_{T}^{0}=\Delta H_{T}^{0}-T \times \Delta S_{T}^{0}
\end{aligned}
$$

where $\Delta \mathrm{H}_{\mathrm{T}}^{0}$ and $\Delta \mathrm{H}_{298}^{0}$ are the standard enthalpy changes of formation of the compound at $\mathrm{T}$ and $298^{\circ} \mathrm{K}$, respectively;

$\Delta \mathbf{S}_{\mathrm{T}}^{\mathrm{O}}$ and $\Delta \mathbf{S}_{298}^{0}$ are the standard entropy changes of formation of the compound at $\mathrm{T}$ and $298^{\circ} \mathrm{K}$, respectively; and $\Delta G_{T}^{0}$ is the standard free energy change of formation of the compound at $\mathrm{T}^{0} \mathrm{~K}$.

The standard free energy change of formation of zinc hydroxide, as a function of temperature, can be calculated from the following expressions ${ }^{(27)}$ :

$$
\begin{aligned}
& \mathrm{Zn}(\mathrm{OH})_{2}(\mathrm{~s})+2 \mathrm{e}^{-}=\mathrm{Zn}(\mathrm{s})+2 \mathrm{OH}^{-}(\mathrm{aq}) \\
& \mathrm{V}_{\mathrm{T}}^{0}=-1.245-0.131 \times 10^{-3}(\mathrm{~T}-298) \text { volts } \\
& \frac{1}{2} \mathrm{O}_{2}(\text { dissolved })+\mathrm{H}_{2} \mathrm{O}(1)+2 \mathrm{e}^{-}=2 \mathrm{OH}^{-}(\mathrm{aq}) \\
& \mathrm{V}_{\mathrm{T}}^{0}=0.401-0.809 \times 10^{-3}(\mathrm{~T}-298) \text { volts }
\end{aligned}
$$

where $V_{T}^{0}$ is the standard electrochemical potential for the corresponding half-cell reaction at $T^{0} \mathrm{~K}$. Combining the Reactions (32) and (34), as well as Eqs. (33) and (35), gives: 


$$
\begin{aligned}
& \mathrm{Zn}(\mathrm{s})+\frac{1}{2} \mathrm{O}_{2} \text { (dissolved) }+\mathrm{H}_{2} \mathrm{O}(1)=\mathrm{Zn}(\mathrm{OH})_{2}(\mathrm{~s}) \\
& \mathrm{E}_{\mathrm{T}}^{0}=1.848-0.678 \times 10^{-3} \mathrm{~T} \text { volts }
\end{aligned}
$$

where $\mathrm{E}_{\mathrm{T}}^{0}$ is the standard electrochemical potential of Reaction (36) at $T^{0} \mathrm{~K}$. The relationship between the standard free energy change and the standard electrochemical potential for the same reaction is given by the following equation:

$$
\Delta G_{T}^{0}=-\mathrm{nEE}_{\mathrm{T}}^{0}
$$

where $\mathrm{n}$ is 2 , i.e., the number of electrons involved in the Reaction (36);

$F$ is the Faraday constant, (96490 Coulombs); and $\Delta G_{T}^{0}$ is the standard free energy change of Reaction (36) at $\mathrm{T}^{0} \mathrm{~K}$.

Combining Eqs.(37) and (38), and substituting for the numerical values of $\mathrm{n}$ and $\mathrm{F}$, gives the following expression for $\Delta G_{T}^{0}$ :

$$
\Delta G_{T}^{0}=31.272 T-85,238 \mathrm{cals}
$$

The formation reaction of $\mathrm{H}_{2} \mathrm{O}(1)$ and its standard free energy change at various temperatures are given by the following expressions $^{(25)}$ : 


$$
\begin{aligned}
\mathrm{H}_{2}(\mathrm{~g}) & +\frac{1}{2} \mathrm{O}_{2} \text { (dissolved) }=\mathrm{H}_{2} \mathrm{O}(\mathrm{I}) \\
\Delta \mathrm{G}_{\mathrm{T}}^{0}= & -70,600-18.31 \mathrm{~T} \times \log \mathrm{T}+0.00064 \mathrm{~T}^{2}- \\
& 4000 / \mathrm{T}+91.75 \mathrm{~T} \text { cals }
\end{aligned}
$$

Combining Eqs.(41) and (39) gives the standard free energy change of formation of zinc hydroxide, as follows:

$$
\begin{aligned}
\Delta G_{T}^{0}= & -155,838-18.31 \mathrm{~T} \times \log \mathrm{T}+0.00064 \mathrm{~T}^{2}- \\
& 4000 / \mathrm{T}+123.02 \mathrm{~T} \mathrm{cal} / \mathrm{mole}
\end{aligned}
$$

The standard free energy change of formation of goethite at $25^{\circ} \mathrm{C}$ is $-116766 \mathrm{cals}$ per mole $\mathrm{e}^{(26)}$. Since the temperature coefficients of the standard heat capacity for goethite (FeOOH) were not available, its standard free energy change of formation in the temperature range of 20 to $80^{\circ} \mathrm{C}$ was assumed to be the same as that at $25^{\circ} \mathrm{C}$.

The standard free energy change of formation for all the elements and compounds of interest, as shown in Table 3, was calculated and is listed in Appendix D.

\section{5-1-2 Calculation of Standard Eree Energy Change of Reaction}

The standard free energy change of a reaction is the difference between the summation of the standard free energy change of formation for all the products and that for all the reactants in the reaction. Therefore, if the standard free 
energy of formation for all the species involved in a reaction are known, the standard free energy change of the reaction can be calculated according to the following equation:

$$
\Delta G_{\mathrm{T}, \mathrm{r} g \mathrm{n}}^{0}=\Sigma \Delta \mathrm{G}_{\mathrm{T}, \mathrm{f}}^{0} \text { products }-\Sigma \Delta \mathrm{G}_{\mathrm{T}, \mathrm{f}}^{\mathrm{O}} \text { reactants }
$$

where $\Delta G_{T, r \times n}^{0}$ is the standard free energy change of reaction at $\mathrm{T}^{\mathrm{O}} \mathrm{K}$, and $\Delta \mathrm{G}_{\mathrm{T}, \mathrm{f}}^{\mathrm{O}}$ is the standard free energy change of formation for the species at $\mathrm{T}^{0} \mathrm{~K}$. Values of $\Delta \mathrm{G}_{\mathrm{T} \text {.rxn }}^{0}$ for the reactions listed in Tables 3 and 4 are presented and discussed in Chapter 6 .

\section{5-2 Experimental Determination of Standard Electrochemical} Potential for Zinc and Iron

The half-cell reactions for zinc and iron are as follows:

$$
\begin{aligned}
& \mathrm{Zn}^{2+}(\mathrm{aq})+2 \mathrm{e}^{-}=\mathrm{Zn}(\mathrm{s}) \\
& \mathrm{Fe}^{2+}(\mathrm{aq})+2 \mathrm{e}^{-}=\mathrm{Fe}(\mathrm{s})
\end{aligned}
$$

The standard electrochemical potentials, $V_{T}^{0}$, of the above reactions, over the temperature range of $25^{\circ} \mathrm{C}$ to $80^{\circ} \mathrm{C}$, were computed from the measured electrochemical potentials in 0.010 molal electrolytes.

In the case of $z$ inc, the electrochemical potential, $V_{T}$, was measured at 25,50 , and $80^{\circ} \mathrm{C}$, in a 0.010 molal zinc 
chloride solution. Similarly, the electrochemical potential of iron was measured at the same temperatures in a 0.010 molal solution of ferrous chloride. These measured electrochemical potentials are presented in Chapter 6 .

In the experiment, a saturated calomel electrode (SCE) was used as a reference electrode, and the electrochemical potential of SCE at various temperatures can be calculated according to the following equation ${ }^{(27)}$ :

$$
V(t)=0.2415+0.165 \times 10^{-3}(t-25)
$$

where $t$ is the temperature in degrees Celsius, and $V(t)$ is the electrochemical potential of SCE in volt at $t^{\circ} \mathrm{C}$ vs. NHE at $25^{\circ} \mathrm{C}$. Subtracting the potential of SCE from the potential reading experimentally obtained for the zinc or iron electrode gives the electrochemical potential, with respect to NHE at $25^{\circ} \mathrm{C}$, of the zinc or iron electrode tested.

Calculation of standard electrochemical potential, $V_{T}^{0}$, from the measured electrochemical potential, $V_{T}$, was performed according to the following relationship:

$$
\mathrm{V}_{\mathrm{T}}^{0}=\mathrm{V}_{\mathrm{T}}-(2.303 \mathrm{RT} / 2 \mathrm{~F}) \log \mathrm{a}_{\mathrm{i}}
$$

where $a_{i}$ is the activity of the zinc or iron ion. The activity of the ion produced by the dissolution of a solute 
can be expressed in terms of the mean ionic molality $m_{m}$ and mean ionic molal activity coefficient $\tau_{\mathbb{m}}$ of the solute according to the following equation:

$$
a_{i}=m_{m} \tau_{m}
$$

For 0.010 molal $\mathrm{ZnCl}_{2}$ or 0.010 molal $\mathrm{FeCl}_{2}$ solutions, the $\mathrm{m}_{\mathrm{m}}$ is, by definition,

$$
m_{n}=(0.010) \times\left(2^{2} \times 1^{1}\right)^{1 / 3}=0.01587
$$

Substituting the Eqs.(48) and (49), and introducing the constant values of $R$ and $F$ into $E q .(47)$ give

$$
\mathrm{V}_{\mathrm{T}}^{0}=\mathrm{V}_{\mathrm{T}}+1.785 \times 10^{-4} \mathrm{~T}-9.922 \times 10^{-5} \mathrm{~T} \times \log \tau_{\mathrm{m}}
$$

In the case of the 0.010 molal $\mathrm{ZnCl}_{2}$ solutions, Robinson and stokes $^{(28)}$ listed, as shown in Table 5 , the values of $\tau_{\mathbb{m}}$ from $10^{\circ} \mathrm{C}$ to $40^{\circ} \mathrm{C}$ at every $5^{\circ} \mathrm{C}$ interval. As can be seen from this table, $\tau_{m}$ decreases less than $0.5 \%$ when temperature increases $5^{\circ} \mathrm{C}$. For the temperature range of $20^{\circ} \mathrm{C}$ to $80^{\circ} \mathrm{C}$, the change in $\tau_{\mathbb{m}}$ is less than $30 \%$ if a linear relationship of mean ionic molal activity coefficient and temperature is assumed. As can be evaluated from Eq. (50), the change in $V_{T}^{0}$ due to the $30 \%$ change of $\tau_{\pi}$ is less than $5.5 \mathrm{mv}$, which is negligible as 
Table 5. Mean ionic molal activity coefficients, $\tau$, of 0.010 molal zinc chloride solution at $10^{\circ} \mathrm{C} \leq \mathrm{T} \leq 40^{\circ} \mathrm{C}$ (abstracted from Ref. 20).

\begin{tabular}{ll}
\hline$T\left({ }^{\circ} \mathrm{C}\right)$ & $\tau_{\pi}$ \\
\hline 10 & 0.737 \\
15 & 0.735 \\
20 & 0.733 \\
25 & 0.731 \\
30 & 0.728 \\
35 & 0.726 \\
40 & 0.723 \\
\hline
\end{tabular}


compared to the standard electrochemical potential difference between zinc and iron. Therefore, the activity coefficients of the solutions at 50 and $80^{\circ} \mathrm{C}$ were assumed to be the same as that at $25^{\circ} \mathrm{C}$. In the case of the 0.010 molal $\mathrm{FeCl}_{2}$ solution at $25^{\circ} \mathrm{C}, \tau_{\mathrm{m}}$ was found to be $0.7516^{(29)}$. The mean ionic molal activity coefficient of the 0.010 molal $\mathrm{FeCl}_{2}$ solutions at 50 and $80^{\circ} \mathrm{C}$ were also assumed to be the same as that at $25^{\circ} \mathrm{C}$. This is due to the following two reasons. First, the concentration and the valence type of the $\mathrm{FeCl}_{2}$ solutions for the research experiments are same as those of the $\mathrm{ZnCl}_{2}$ solutions, and thus the temperature dependence of $\tau_{\mathrm{m}}$ for $\mathrm{FeCl}_{2}$ solution is similar to that for $\mathrm{ZnCl}_{2}$. Next, the difference of the standard electrochemical potential between zinc and iron is of interest. It is reasonable to use the same assumption of the temperature dependence of $\tau_{\mathrm{m}}$ in both cases. Once the mean ionic molal activity coefficients are known, the $\mathrm{V}_{\mathrm{T}}^{0}$ can be obtained according to Eq. (50).

The following paragraphs of this section are devoted to a detailed description of the experimental methodology, including preparation of metal electrodes, preparation of electrolytes, and instrumentation.

\section{5-2-1 Preparation of Metal Electrodes}

Both zinc and iron, in the form of $0.50 \mathrm{~mm}$ thick sheets, were purchased from Alfa Research Chemicals \& Materials, 
Danvers, Massachusetts. The zinc, which was $99.99 \%$ pure, contained trace amounts of cadmium, indium, copper, iron, silicon and silver. The iron was also $99.99 \%$ pure, with lead as an impurity. Both the zinc and iron were polished first with a 240 and then a 600 grit silicon carbide abrasive paper, washed with deionized water, degreased with acetone, and then rinsed again with deionized water. They were then dipped into 75\% perchloric acid for one minute, dried, and then mounted into the teflon specimen holder shown in Figure 5. The sample was then transferred into the electrolytic solution for measuring the electrochemical potential.

\section{5-2-2 Preparation of Electrolytes}

Zinc and ferrous chlorides, purchased from Alfa Research Chemicals \& Materials, were used separately to produce 0.010 molal electrolytic solutions, as described in the following two paragraphs. For every 500 grams of deionized water, 0.2 gram of $37 \%$ of hydrochloric acid was added, and thus the electrolytes had a 0.004 molal $\mathrm{HCl}$ concentration. Assuming total dissociation of the $\mathrm{HCl}$, this concentration corresponds to a $\mathrm{pH}$ value of 2.40 . This was done to prevent the formation of oxide or hydroxide films on the electrode surface. Another purpose of the $\mathrm{HCl}$ addition was to keep the $\mathrm{pH}$ of the electrolytes practically constant over the temperature range of 25 to $80^{\circ} \mathrm{C}$. This effect can be expected since the $\mathrm{pH}$ of 


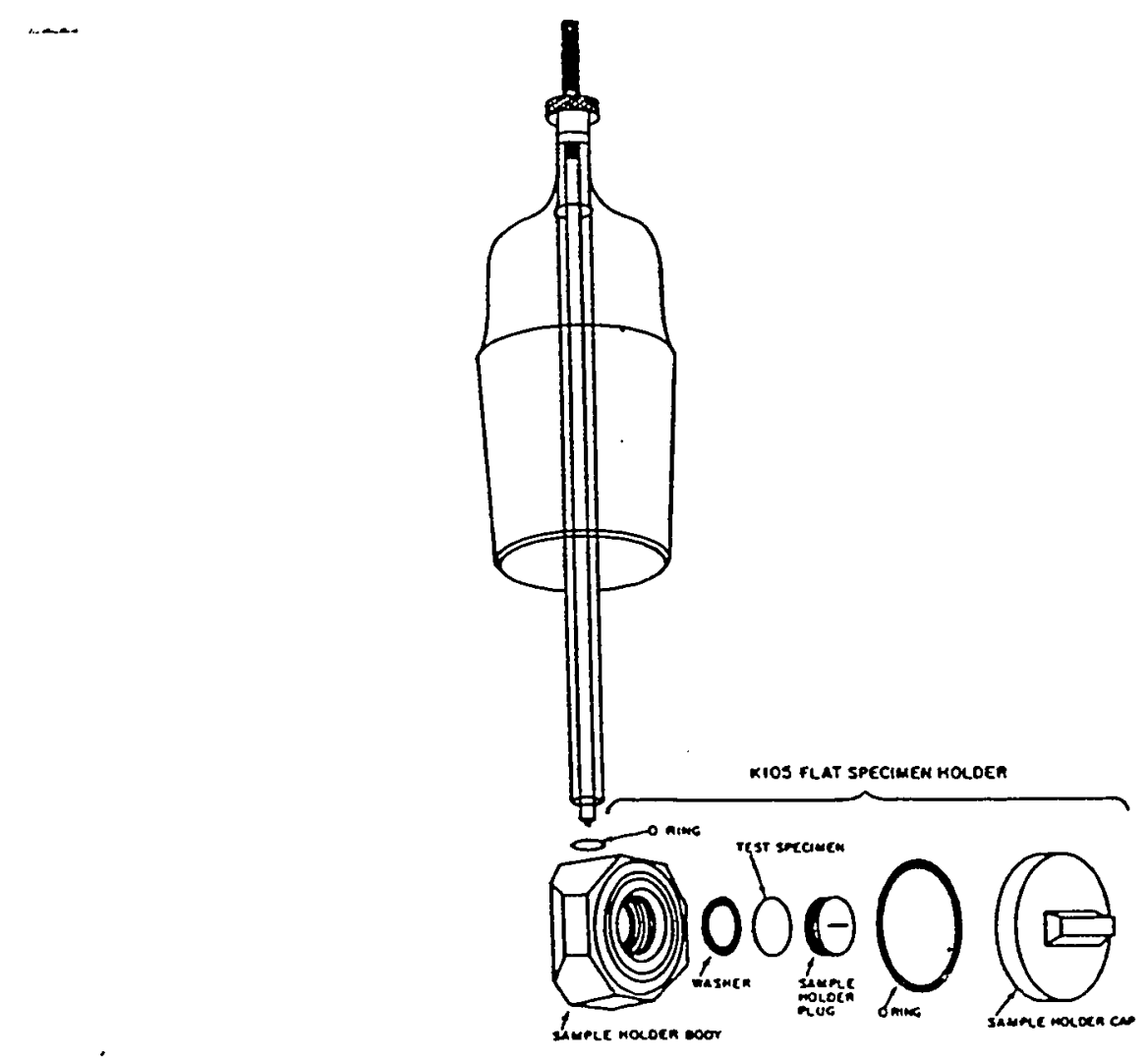

Eigure 5. Exploded view of specimen holder (after Model K47 Corrosion Cell system, Instruction Manual, EG\&G Princeton Applied Research). 
neutral water at $25^{\circ} \mathrm{C}$ is 7.0 , and at $80^{\circ} \mathrm{C}$ is 6.3 . These values can be calculated according to the following equation ${ }^{(30)}$ :

$$
\mathrm{pH}=2235.99 / \mathrm{T}-3.0438+\overrightarrow{0.00853 T}
$$

where $T$ is the temperature of the neutral water in degrees Kelvin. Therefore, the concentration of the hydrogen ion came mainly from the addition of the HCl, and was the same for all the electrolytes used. The temperature induced $\mathrm{pH}$ change of the deionized water is therefore not sufficiently large to affect the $\mathrm{pH}$ of the electrolyte.

Approximately 22 grams of $\mathrm{ZnCl}_{2}$ anhydrous powder, technical grade, were dissolved in 250 grams of deionized water that had previously been sparged with nitrogen gas. The solution was heated to $50^{\circ} \mathrm{C}$ to aid $\mathrm{ZnCl}_{2}$ dissolution. The concentration of the solution was then determined gravimetrically by precipitation as $\mathrm{AgCl}$, and was found to be 0.0798 gram of $\mathrm{ZnCl}_{2}$ per gram of solution. This solution was then stored under a flowing $\mathrm{N}_{2}$ atmosphere, and served as the mother solution. The 0.010 molal experimental solution was then made by adding 8.686 grams of the mother solution to 500 grams of deionized water.

Due to the unstable nature of $\mathrm{FeCl}_{2}$ solutions, the 0.010 molal $\mathrm{FeCl}_{2}$ solution was produced each time by dissolving 0.636 gram of $\mathrm{EeCl}_{2}$ anhydrous powder, technical grade, in 500 
grams of deionized water.

\section{5-2-3 Instrumentation}

A model 273 potentiostat and model $\mathrm{K} 47$ corrosion cell, both made by EG\&G Princeton Applied Research, were used together to measure the electrochemical potential of the samples with respect to a saturated calomel electrode (SCE). These instruments are shown in Eigures 6 and 7 , respectively. Figure 8 is a schematic diagram showing the system assembly. The electrolyte contained in the cell was preheated by a heater to the desired temperature, and then transferred to the water bath maintained at the same temperature by a temperature controller. Before the metal electrode was put into the corrosion flask, the electrolytic solution was sparged with nitrogen gas for five minutes to remove any dissolved oxygen in the solution. The electrochemical potential measurement was started immediately after the metal electrode was put into the electrolyte. The temperature of the electrolyte was maintained to within two degree Celsius of the desired value. 


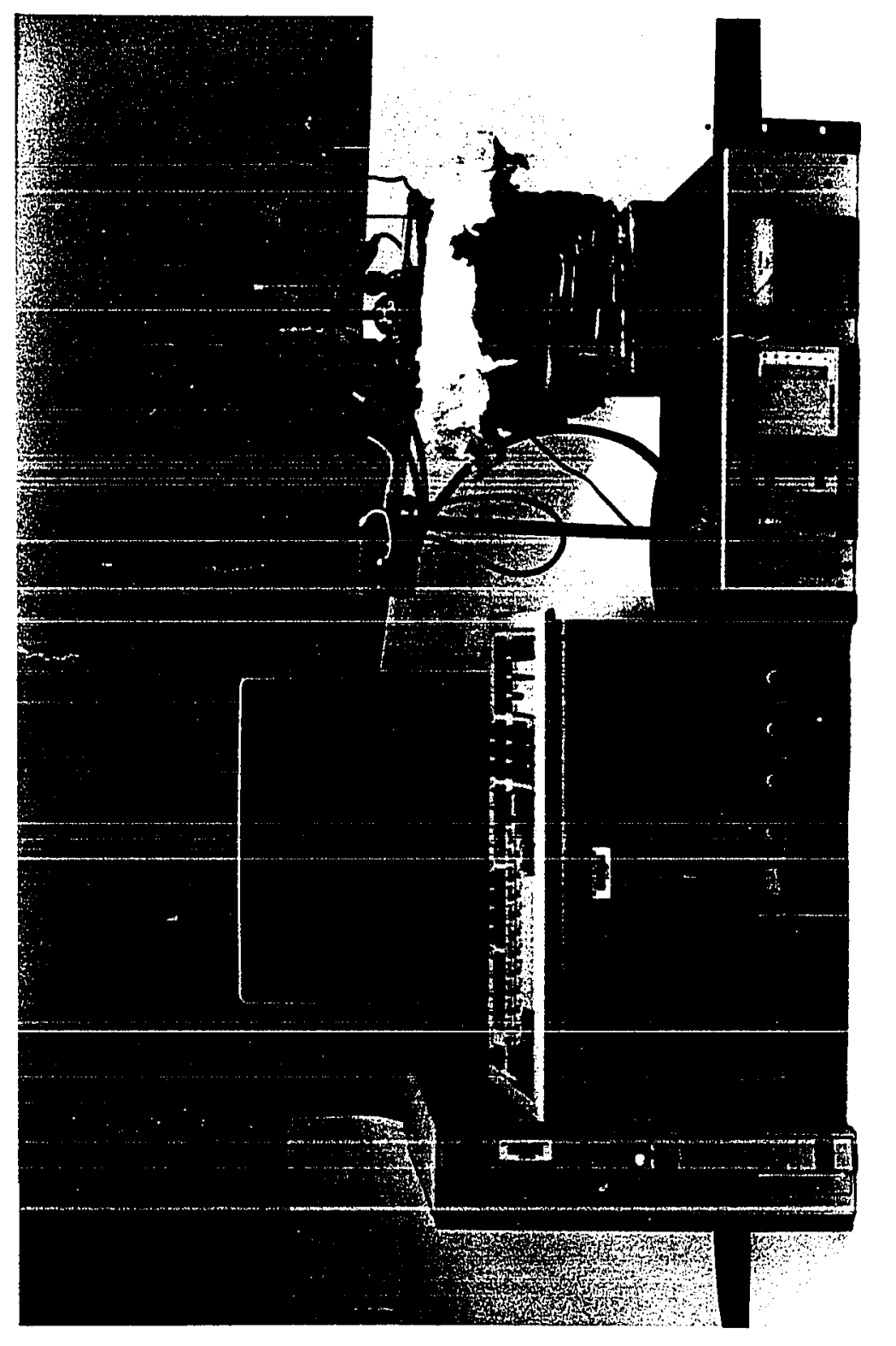

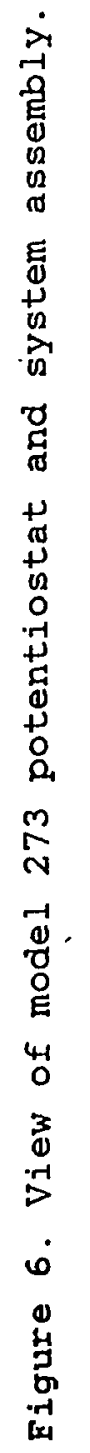




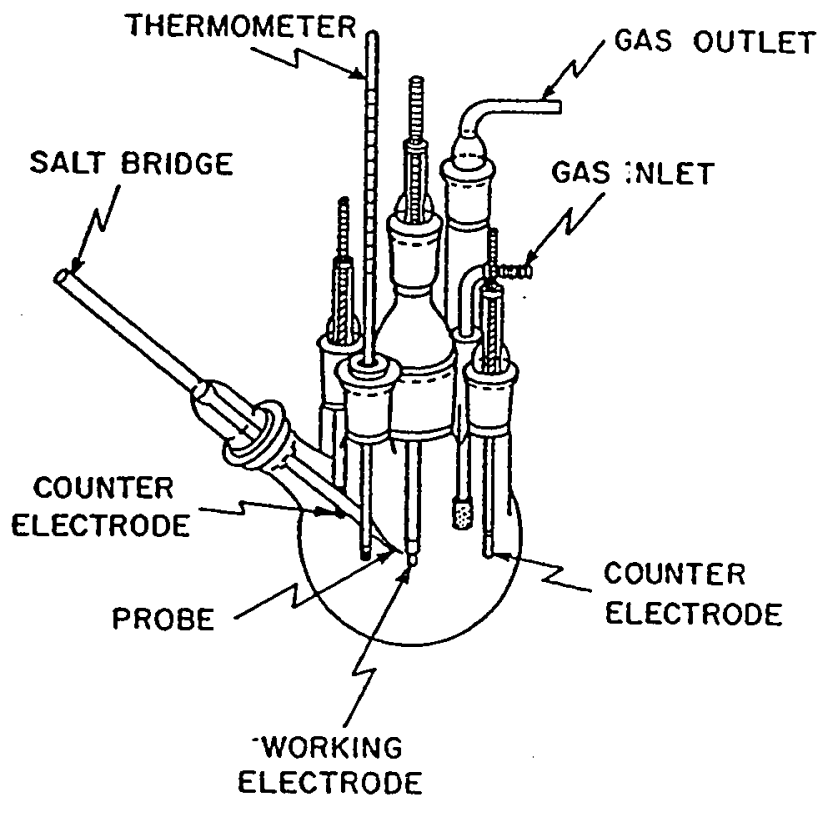

Figure 7. Schematic diagram of corrosion cell system (after G5-82, 1983 Annual Book of American Society for Testing and Materials standards, Vo1. 03.02, p. 122). 


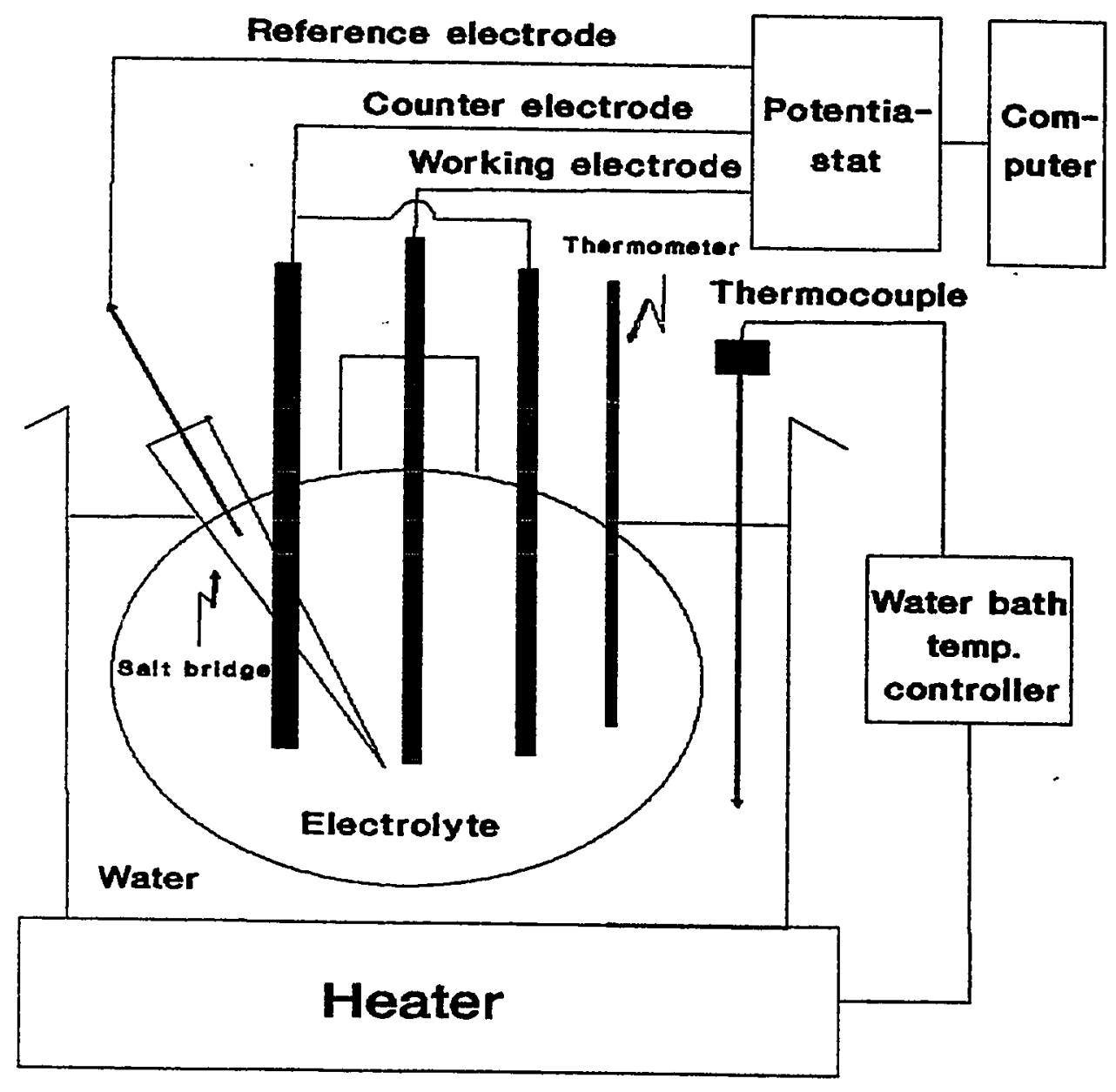

Figure 8. Schematic diagram of system assembly. 
Chapter 6. RESULTS OF RESEARCH INVESTIGATION

The results obtained from methods of investigation outlined in Chapter 5 are contained in this chapter. Section 6-1 shows the results of the theoretical computations, while the results of the experimental investigation are presented in Sections 6-2, 6-3, and 6-4. Section 6-2 contains the results obtained from electrochemical potential measurements in zinc, and section 6-3 those from iron. The results are compared with each other in section 6-4.

\section{6-1 Calculation Results of Standard Eree Energy Change of Reactions}

For the purposes of this investigation, it is the formation of zinc and iron compounds in an aqueous environment that is of interest. These formation reactions, i.e., the oxidation reactions of zinc and iron in an aqueous environment, have been previously discussed, and the relevant reactions presented in Table 3 . The standard free energy changes of these reactions were calculated according to the procedure outlined in Chapter 5, and the results are shown in Table 6.

As can be seen from this table, the standard free energy changes associated with the reactions leading to $\mathrm{ZnO}$ and $\mathrm{Zn}(\mathrm{OH})_{2}$ formation are far more negative than those leading to 


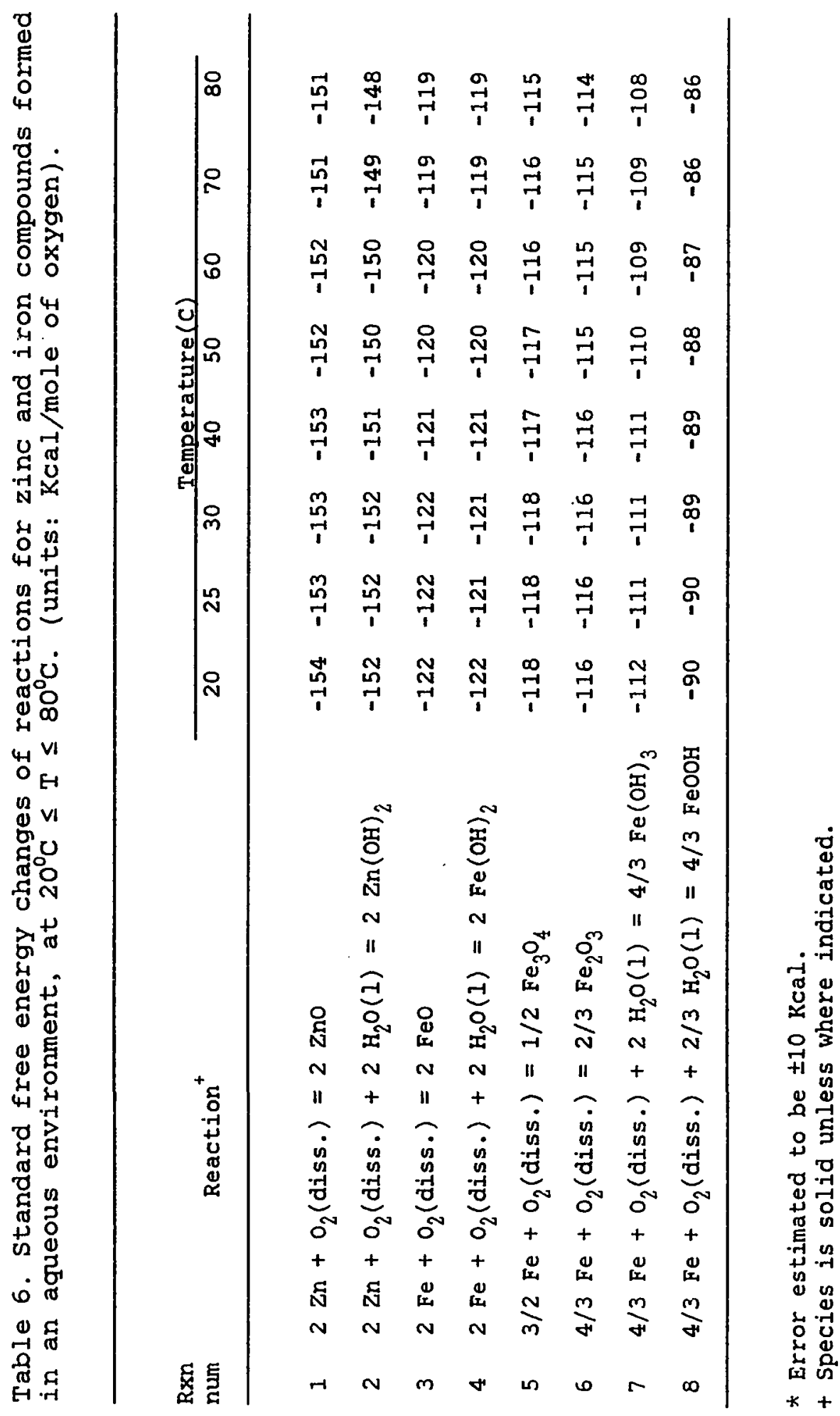


iron compound formation. Furthermore, it can be seen that the above statement is true for the entire temperature range of 20 to $80^{\circ} \mathrm{C}$, and therefore zinc compounds are far more likely to be formed than iron compounds.

Zinc is therefore found to be more easily oxidized than iron over this temperature range, and would also remain anodic to iron over the same temperature range.

The above results showed that the oxidation potential for zinc, in an aqueous environment, is always greater than that for iron over the temperature range of 20 to $80^{\circ} \mathrm{C}$. However, it is possible that there could be interaction between elemental iron and zinc compounds, that could lead to oxidation of iron, with reduction of the zinc compound. If this were to happen, then it would be conceivable that there could be situations under which iron could be anodic with respect to zinc.

The possible oxidation-reduction reactions between elemental zinc and iron compounds, in an aqueous environment, were therefore investigated, and have been reported previously in Table 4. If the standard free energy change of reaction for any of these reactions is negative, it means that zinc will be oxidized. Conversely, if the standard free energy change of reaction were positive, then it is the iron which will be oxidized, or be anodic to zinc. The standard free energy change of reaction of all 34 reactions listed in Table 
4 were calculated for the temperature range of 20 to $80^{\circ} \mathrm{C}$, and are reported in Tables 7,8 , and 9 .

Table 7 contains those reactions whose standard free energy change of reaction is more than $-20 \mathrm{Kcal} / \mathrm{mole}$ of $\mathrm{zinc}$, Table 8 contains those between -50 and $-20 \mathrm{Kcal} / \mathrm{mole}$ of $\mathrm{zinc}$, and Table 9 contains those that are less than $-50 \mathrm{Kcal} / \mathrm{mole}$ of zinc. The error margin for all the data reported is \pm 10 Kcal.

It is seen that the standard free energy change of reactions, for all 34 reactions, are negative over the temperature range of 20 to $80^{\circ} \mathrm{C}$. This means that elemental zinc will be oxidized by iron compounds, via all of the postulated reaction mechanisms, and will therefore always be anodic with respect to iron.

The standard free energy change of reactions for the Reactions (4) and (21) are found to be have numerical values less than $10 \mathrm{Kcal}$, which is the error margin of the data reported here. It is therefore conceivable that these two reactions could proceed backward, thus leading to iron being anodic with respect to zinc.

However, in the presence of excess water, it is found that Reaction (5) will dominate over (4) and Reaction (22) will dominate over (21). It can therefore be concluded that Reactions (4) and (21) will not lead to any back reactions because of the existence of competing reactions that can 


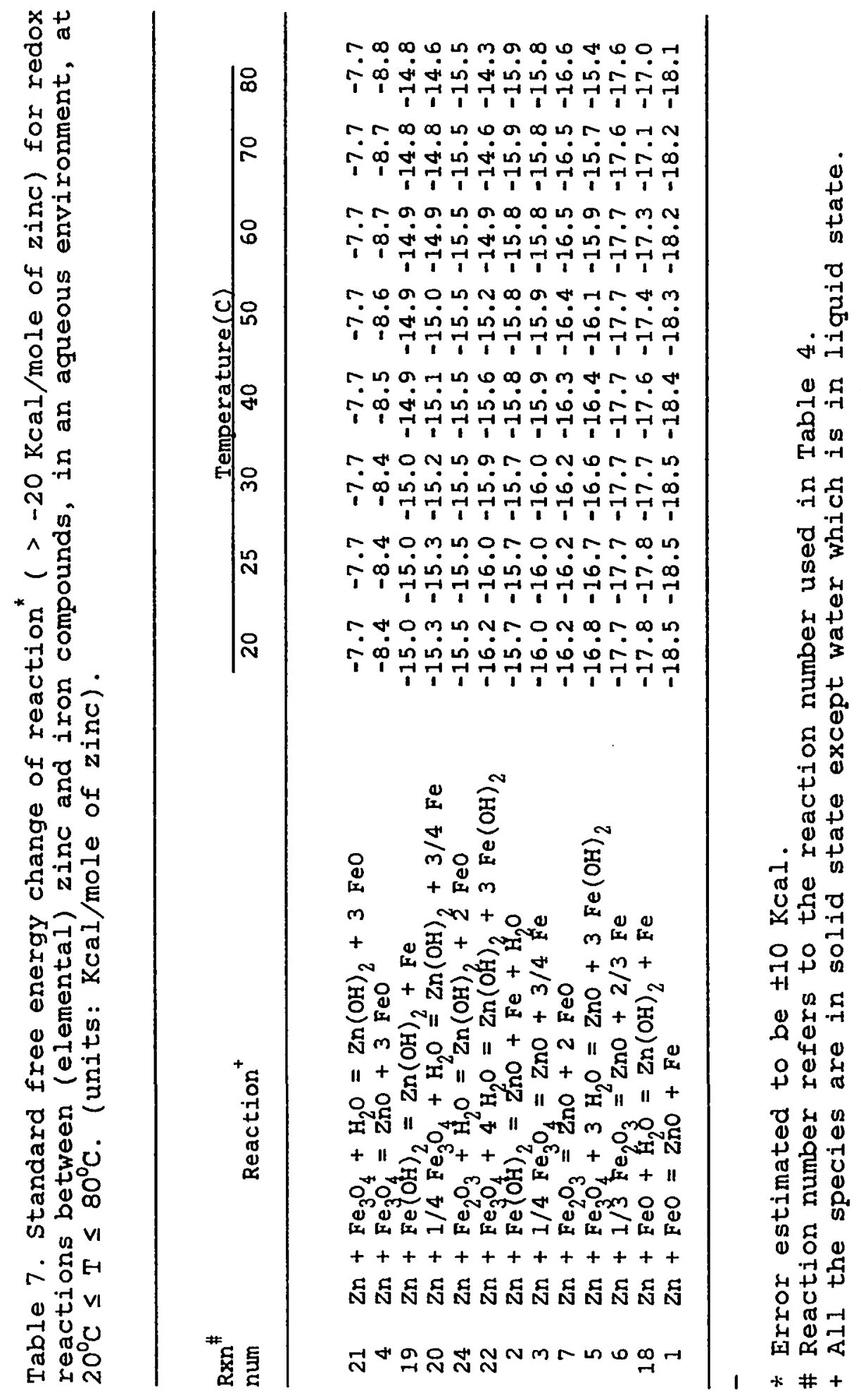




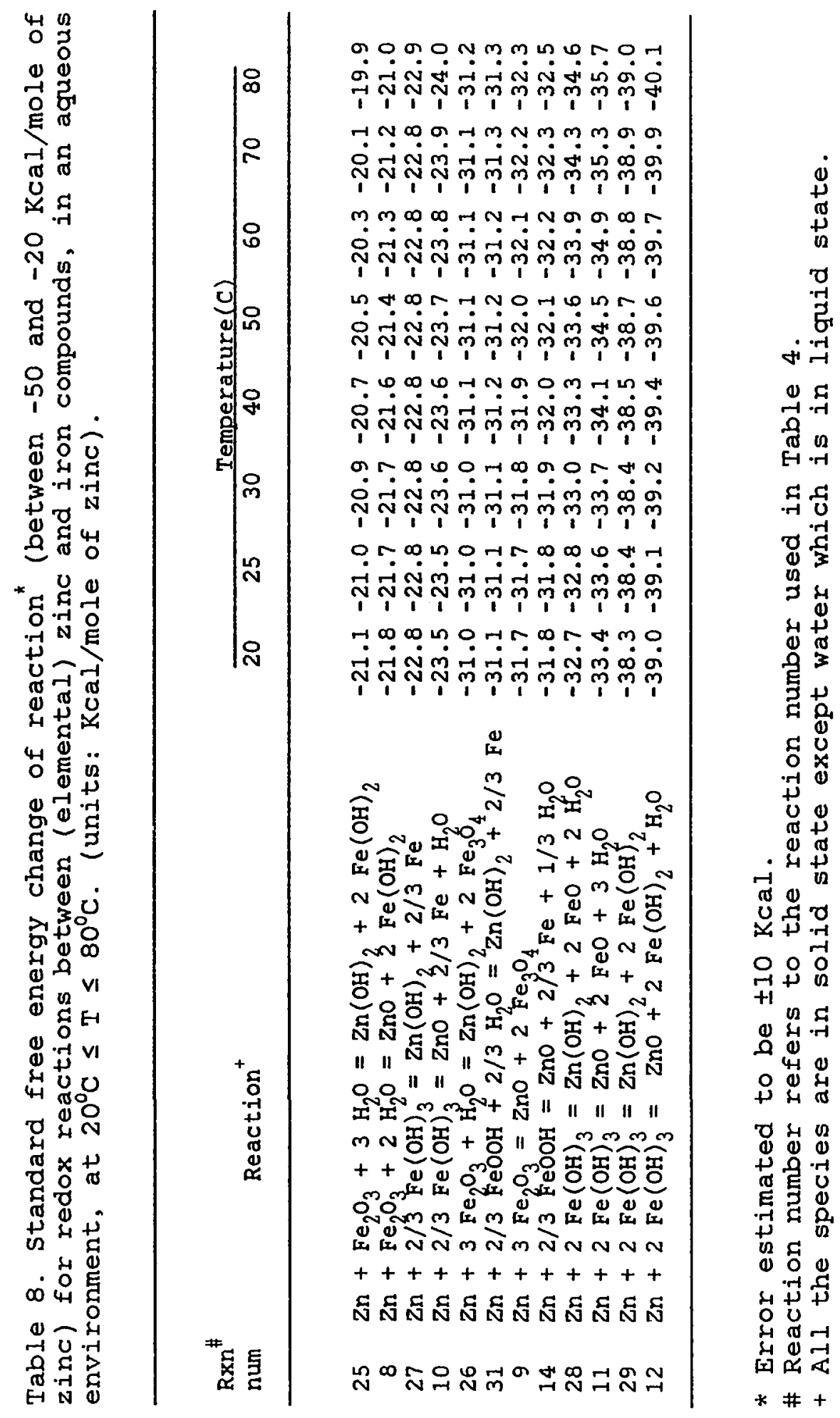




\begin{tabular}{|c|c|c|c|}
\hline 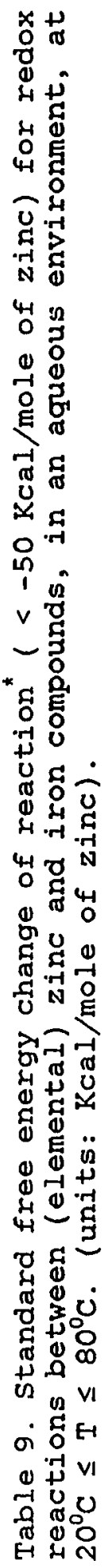 & $\mid \begin{array}{l}\infty \\
0 \\
0 \\
0 \\
0\end{array}$ & 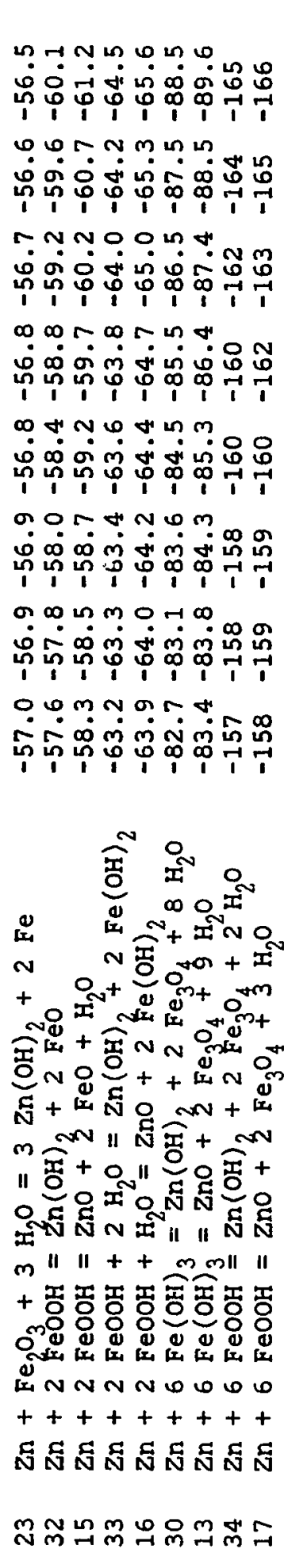 & 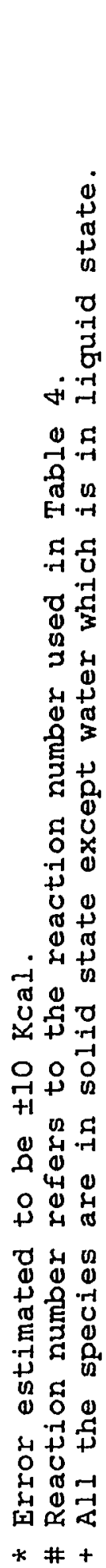 \\
\hline
\end{tabular}


dominate these.

If there exists a temperature, $\mathrm{T}_{\mathrm{PR}}$, at which the standard electrochemical potential of zinc and iron reverse themselves, then, for $T>T_{P R}$, at least one of the reactions listed in Table 4 should have a positive standard free energy change of reaction. This is a necessary condition for iron to exhibit any form of anodicity towards zinc. This investigation shows that for zinc and iron in an aqueous environment, zno or $\mathrm{Zn}(\mathrm{OH})_{2}$ is always more stable than any corresponding iron compounds.

It can therefore be concluded, based on theoretical calculations, that zinc is anodic to iron over the temperature range of 20 to $80^{\circ} \mathrm{C}$, and that there is no "Potential Reversal." Therefore, if other investigators have detected such a phenomenon, it must be an artifact of some other conditions. This is discussed further in Chapter 7.

\section{6-2 Standard Electrochemical Potential of zinc}

The measured electrochemical potential of zinc $\left(V_{\text {mean }}\right)$ is listed in Table 10. Eive measurements were made at each temperature, and the mean value, $V_{\text {mean }}$, was determined. The standard electrochemical potential, $V_{T}^{0}$, was computed according to the procedure outlined in Chapter 5, and are listed in this table. For purposes of comparison, published values of $V_{T}^{0}$ are also 1 isted in this table. The error between the published 
Table 10. Experimentally determined values and published values for the standard electrochemical potential of zinc vs. NHE at $25^{\circ} \mathrm{C}$ (solution: $0.010 \mathrm{~m} \mathrm{ZnCl}_{2}$ ).

\begin{tabular}{|c|c|c|c|c|c|c|}
\hline $\begin{array}{r}\text { Temp } \\
\text { (C) }\end{array}$ & $\mathrm{V}_{\mathrm{mean}}$ & $\tau_{\mathrm{m}}$ & $\begin{array}{l}V_{\text {exp }}^{0} \\
m v\end{array}$ & $V_{\text {pub }}^{0}{ }_{\text {thv }}^{*}$ & $\begin{array}{c}\text { Erro } \\
\text { mv }\end{array}$ & $\begin{array}{c}\mathrm{p}-\mathrm{pub} \\
\%\end{array}$ \\
\hline $\begin{array}{l}25 \\
50 \\
80\end{array}$ & $\begin{array}{l}-806 \\
-783 \\
-770\end{array}$ & $\begin{array}{l}0.731^{+} \\
0.731 \\
0.731\end{array}$ & $\begin{array}{l}-749 \\
-721 \\
-701\end{array}$ & $\begin{array}{l}-763 \\
-739 \\
-710\end{array}$ & $\begin{array}{r}14 \\
18 \\
9\end{array}$ & $\begin{array}{r}1.8 \\
2.5 \\
1.2\end{array}$ \\
\hline
\end{tabular}

\# Error margin: $\pm 5 \mathrm{mv}$.

* Data after Ref. 23.

+ Data after Ref. 28. 
values and the values obtained in the course of this investigation was found to be less than $2.5 \%$.

\section{6-3 Standard Electrochemical potential of iron}

The measured electrochemical potential of iron $\left(V_{\text {mean }}\right)$ is listed in Table 11. Five measurements were made at each temperature, and the mean value, $V_{\text {mean }}$, was determined. The standard electrochemical potential, $V_{T}^{0}$ was computed according to the procedure outlined in Chapter 5, and are listed in Table 11. Published values of $V_{T}^{0}$ are also listed in this table. The error between the published values and the values measured in the course of this investigation, was found to be less than $18.8 \%$.

\section{6-4 Standard Electrochemical Potential Differences between Zinc and Iron}

The measured and published standard electrochemical potentials of $\mathrm{zinc}$ and iron are tabulated in Table 12, and plotted in Figure 9. As can be seen in this figure, the standard electrochemical potential was found to increase with temperature, and the increase appears to be linear. No occurrence of potential reversal between zinc and iron, for temperatures up to $80^{\circ} \mathrm{C}$, was found.

Both the theoretical and the experimental approaches show that zinc is anodic to iron over the temperature range of 20 
Table 11. Experimentally determined values and published values for the standard electrochemical potential of iron vs. NHE at $25^{\circ} \mathrm{C}$ (solution: $0.010 \mathrm{~m} \mathrm{FeCl}_{2}$ ).

\begin{tabular}{|c|c|c|c|c|c|c|}
\hline $\begin{array}{r}\text { Temp } \\
\text { (C) }\end{array}$ & $\mathrm{v}_{\text {mean }}^{\#}$ & $\tau_{\mathbb{n}}$ & $v_{\operatorname{mpp}}^{0}$ & $\mathrm{~V}_{\mathrm{pub}}^{0}{ }_{\mathrm{mv}}^{*}$ & $\begin{array}{c}\text { Error } \\
\text { mv }\end{array}$ & $\underset{\%}{\mathrm{xp}-\mathrm{pub})}$ \\
\hline $\begin{array}{l}25 \\
50 \\
80\end{array}$ & $\begin{array}{l}-444 \\
-401 \\
-395\end{array}$ & $\begin{array}{l}0.7516^{+} \\
0.7516 \\
0.7516\end{array}$ & $\begin{array}{r}-387 \\
-339 \\
-328\end{array}$ & $\begin{array}{l}-440 \\
-417 \\
-389\end{array}$ & $\begin{array}{c}54 \\
78 \\
62\end{array}$ & $\begin{array}{c}12.17 \\
18.72 \\
15.82\end{array}$ \\
\hline
\end{tabular}

\# Error margin: $\pm 5 \mathrm{mv}$.

* Data after Ref. 23.

+ Data after Ref. 29. 
Table 12. Standard electrochemical potential differences between zinc and iron (units: millivolts vs. NHE at $25^{\circ} \mathrm{C}$ ).

\begin{tabular}{|c|c|c|c|c|c|c|}
\hline \multirow{2}{*}{$\begin{array}{l}\text { Temp } \\
\text { (C) }\end{array}$} & \multicolumn{3}{|c|}{ Experimental } & \multicolumn{3}{|c|}{ Published" } \\
\hline & $\mathrm{Zn}$ & $\mathrm{Ee}$ & $\mathrm{Zn}-\mathrm{Ee}$ & $\mathrm{Zn}$ & $\mathrm{Fe}$ & $\overline{\mathrm{Zn}-\mathrm{Fe}}$ \\
\hline $\begin{array}{l}25 \\
50 \\
80\end{array}$ & $\begin{array}{l}-749 \\
-721 \\
-701\end{array}$ & $\begin{array}{l}-387 \\
-339 \\
-328\end{array}$ & $\begin{array}{l}-362 \\
-382 \\
-374\end{array}$ & $\begin{array}{l}-763 \\
-739 \\
-710\end{array}$ & $\begin{array}{l}-440 \\
-417 \\
-389\end{array}$ & $\begin{array}{l}-323 \\
-322 \\
-321\end{array}$ \\
\hline
\end{tabular}

* Data after Ref. 23. 


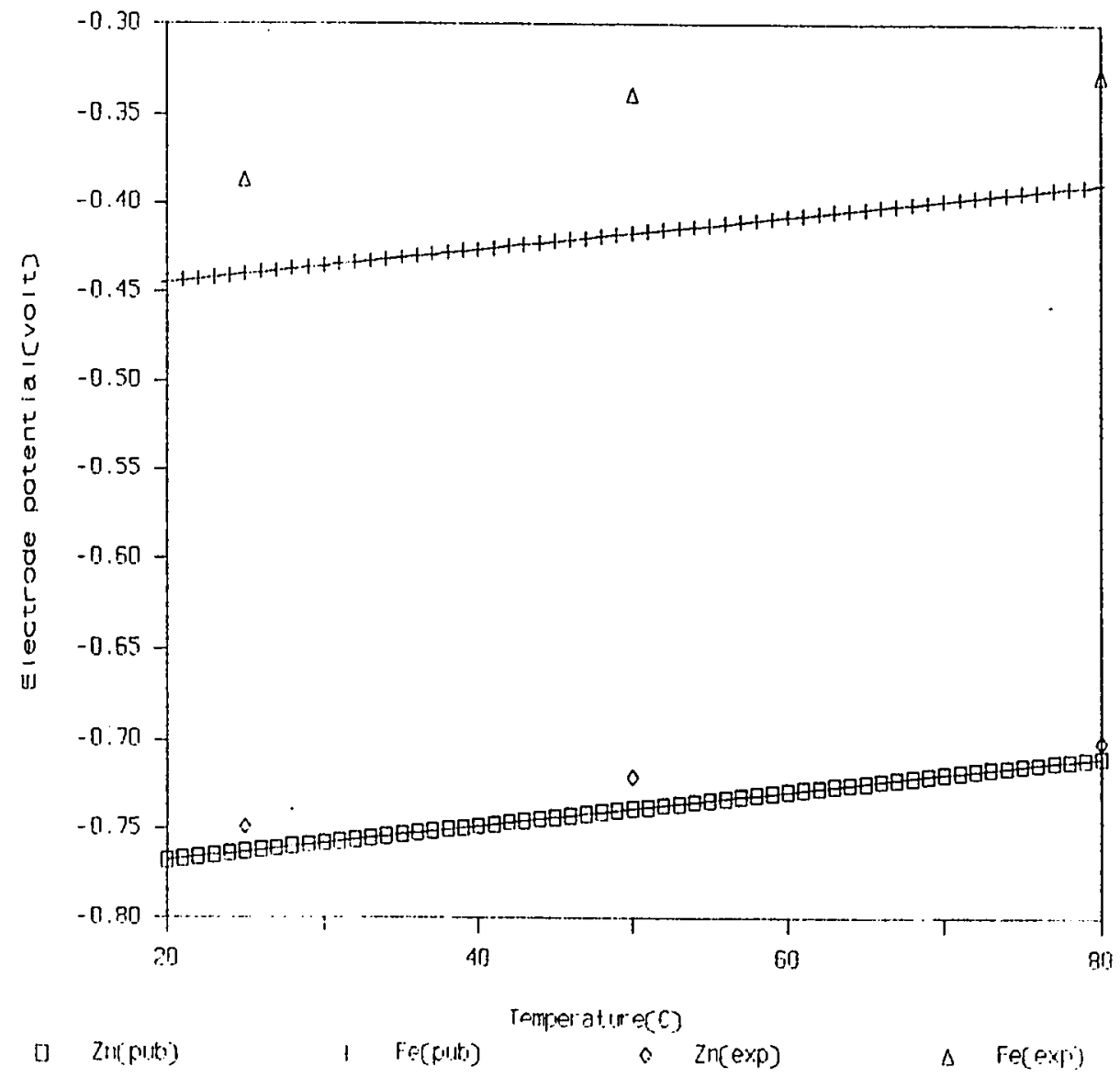

Figure 9. The experimental and published (Ref. 23) values of the standard electrochemical potentials for $z i n c$ and iron at various temperatures vs. NHE at $25^{\circ} \mathrm{C}$. 
to $80^{\circ} \mathrm{C}$, and that there is no potential reversal between them. The significance of the findings from this investigation, and reconciliation of these results with the findings of other investigators who detected the occurrence of zinc-iron potential reversals will be discussed in the next chapter. 
Chapter 7. DISCUSSION AND INTERPRETATION OE POTENTIAL REVERSAL

From the theoretical and experimental results, discussed in Chapter 6 , zinc has been found to be always anodic to iron for the temperature range of 20 to $80^{\circ} \mathrm{C}$, i.e., there is no reversal in the standard electrochemical potential between the two.

The potential reversal between zinc and iron that was found by previous investigators ${ }^{(3-9)}$ arises from the facts that (1) galvanized steel samples pitted deeper than iron samples in hot water systems ${ }^{(5,6)}$; (2) the flow of closed-circuit current between zinc and iron couples changes direction after some definite time, at some particular conditions ${ }^{(3.4 .7 .8 .9)}$; and/or (3) the value of a single electrode potential measured under closed-circuit conditions was more negative for iron than for $z$ inc ${ }^{(7,8)}$. In the case of the first fact, deeper pitting in galvanized steel does not necessarily mean that zinc and iron reverse their standard electrochemical potentials, since the corrosion products formed on the zinc surface of the galva-nized steel interrupted the protection of the base steel by the zinc coating. In the case of the other two facts, the electrode potential measured under closed-circuit conditions is not an electrochemical potential, especially when the surface of the electrode is covered by the corrosion products. Therefore, the change of current 
direction or the greater potential for the zinc electrode than for the iron electrode cannot be considered as sufficient evidence for the occurrence of an electrochemical potential reversal. As was discussed in section 2-5, an electrode is no longer at equilibrium when a net current flows to or from its surface. The electrode potential measured by some of the previous investigators is the corrosion potential which is different from the electrochemical potential. It is therefore obvious that the potential, which was been found to be reversed, is the corrosion potential, and not the (standard) electrochemical potential.

As was discussed in Chapter 3 , the results of the investigations $^{(3-9)}$ pertaining to the failure of zinc coatings to provide the underlying steel with galvanic protection can be summarized as follows:

(1) Zinc and iron reverse their corrosion potentials in the presence of dissolved oxygen and elevated temperatures, typically $60^{\circ} \mathrm{C}$ or above.

(2) This potential reversal is attributed to the ennoblement of zinc, i.e., due to the increase of the zinc corrosion potential.

(3) Corrosion products are formed on the surface of $\mathrm{zinc}$, and not on that of iron.

(4) Water composition plays a dominant role on the influence of corrosion potential reversal. 
Examination of the above results indicates that there are three generic factors that play an important role. These are:

(a) The effect of dissolved oxygen,

(b) The effect of temperature, and

(c) The effect of water composition, i.e., the effects of solute in the water.

Besides presenting the summary of the results of this study and the previous investigations, the above discussion points out that the corrosion potential reversal between zinc and iron was found to be dependent on the effects of dissolved oxygen, temperature, and water composition. The influences of these three factors on the corrosion potential of iron and zinc are discussed in sections 7-1, 7-2, 7-3, and 7-4. Section 7-1 discusses the corrosion potentials of steel and zinc in an aqueous environment. Section 7-2 discusses the effect of dissolved oxygen on the corrosion potential of zinc, since change of zinc corrosion potential was found to be responsible for the reversal of polarity. Section 7-3 discusses the effect of temperature on the corrosion potential of zinc, while Section 7-4 discusses the effect of water composition. Section 7-5 interprets, case by case, the findings by previous investigators ${ }^{(3-9)}$.

\section{7-1 Corrosion Potential of Steel and zinc in Aqueous Environment}


The corrosion potential of a metal electrode in aqueous solutions, as discussed in section 2-6, can be raised by any one of the following: (1) an increase in the equilibrium potential (i.e., standard electrochemical potential) of the cathode reaction, $\mathrm{E}_{\text {c.eg; }}$ (2) an increase in the exchange current density of the cathode reaction, $j_{o c}$, or a decrease in that of the anode reaction, $j_{0 a} ;(3)$ an increase in the relative area ratio of the cathode to the anode. The cathode reaction in deaerated water, as discussed in section 2-7, is hydrogen evolution, while in aerated water it is the combination of hydrogen evolution and oxygen reduction. However, in aerated water, one of the cathode reactions may dominate over another, and result in the negligible influence of the latter on the corrosion potential of the electrode. The occurrence of this phenomenon is dependent on the relative magnitude of the exchange current density for the hydrogen evolution and the oxygen reduction on this particular metal electrode. This phenomenon and its resulting influence on the corrosion potential of the metal are discussed in the following sections.

\section{7-1-1 Corrosion Potential of Steel}

In the case of steel, hydrogen evolution dominates over oxygen reduction, since the exchange current density of the oxygen reduction on iron electrodes is small as compared to 
that of hydrogen evolution $\left(10^{-10}\right.$ vs. $\left.10^{-3} \mathrm{amp} / \mathrm{m}^{2}\right)$. As a consequence, the cathodic polarization of iron in aerated water is mainly due to hydrogen evolution, and the dissolved oxygen causes only a negligible increase in the corrosion potential of iron. Therefore, the corrosion potentials in deaerated and aerated waters were found to be approximately equal ${ }^{(4,7,8)}$. The values of these corrosion potentials in the temperature range of 40 to $60^{\circ} \mathrm{C}$ were found ${ }^{(7,8)}$ to be in the range of $0.36-0.45$ volts, negative to a NHE at $25^{\circ} \mathrm{C}$. Moreover, the corrosion potential of this order of magnitude was also observed even though the composition of the water, i.e., the nature and amount of solute in the water, was varied over wide limit ${ }^{(8)}$, and the temperature of the water was varied from 25 to $85^{\circ} \mathrm{C}^{(7)}$. Therefore, in the later discussion of corrosion potential reversal in this study, the standard electrochemical potential of iron at $25^{\circ} \mathrm{C}$, which is -0.44 volts, will be used as the typical value of the corrosion potential for the iron.

\section{7-1-2 Corrosion Potential of Zinc in Deaerated Water}

In the case of zinc in deaerated waters, Gilbert ${ }^{(7)}$ and Hoxeng $^{(8)}$ found that zinc is always anodic to steel for temperatures up to $85^{\circ} \mathrm{C}$. This can be explained by the comparison of the exchange current densities for hydrogen evolution and $2 \mathrm{n}^{2+}-\mathrm{Zn}$ reaction on zinc electrodes. Due to the 
small exchange current of hydrogen evolution on the $\mathrm{Zn}$ surface as compared to the exchange current of $\mathrm{Zn}^{2+} \mid \mathrm{Zn}$ system, the polarization effect of the hydrogen evolution is small, and the corrosion potential of $\mathrm{Zn}$ in deaerated water is about the same as the standard electrochemical potential of $\mathrm{Zn}$ at the same temperature. The highest possible corrosion potential of zinc in deaerated water at $25^{\circ} \mathrm{C}$ can be determined graphically, as shown in Figure 10. The data from Table 2 were used to plot this polarization curve of the zinc electrode, with the assumption of equal cathode and anode areas. In order to obtain the highest possible corrosion potential, $\beta$ was taken to be 0.06 volts, and $j_{0}$ to be $10^{-3} \mathrm{~A} / \mathrm{m}^{2}$ for the $\mathrm{Zn}^{2+} \mid \mathrm{Zn}$ system. The corrosion potential of $\mathrm{zinc}$ under these conditions is approximately -0.67 volts, which is far more negative than the standard electrochemical potential of iron at $25^{\circ} \mathrm{C}$. When the temperature is increased, the equilibrium potentials, $\beta$, and $j_{0}$ for the hydrogen evolution and the zinc oxidation are all increased. Values of these parameters on zinc electrodes at $85^{\circ} \mathrm{C}$ are discussed as follows:

(1) The equilibrium potential of hydrogen at $85^{\circ} \mathrm{C}$ is 0.052 volts, since its temperature coefficient is $0.871 \mathrm{mv} /$ degree (27), and its value at $25^{\circ} \mathrm{C}$ is defined as zero. The equilibrium potential of zinc at $85^{\circ} \mathrm{C}$ is -0.705 volts, since its temperature coefficient is $0.962 \mathrm{mv} /$ degree $^{(23)}$, and its value 


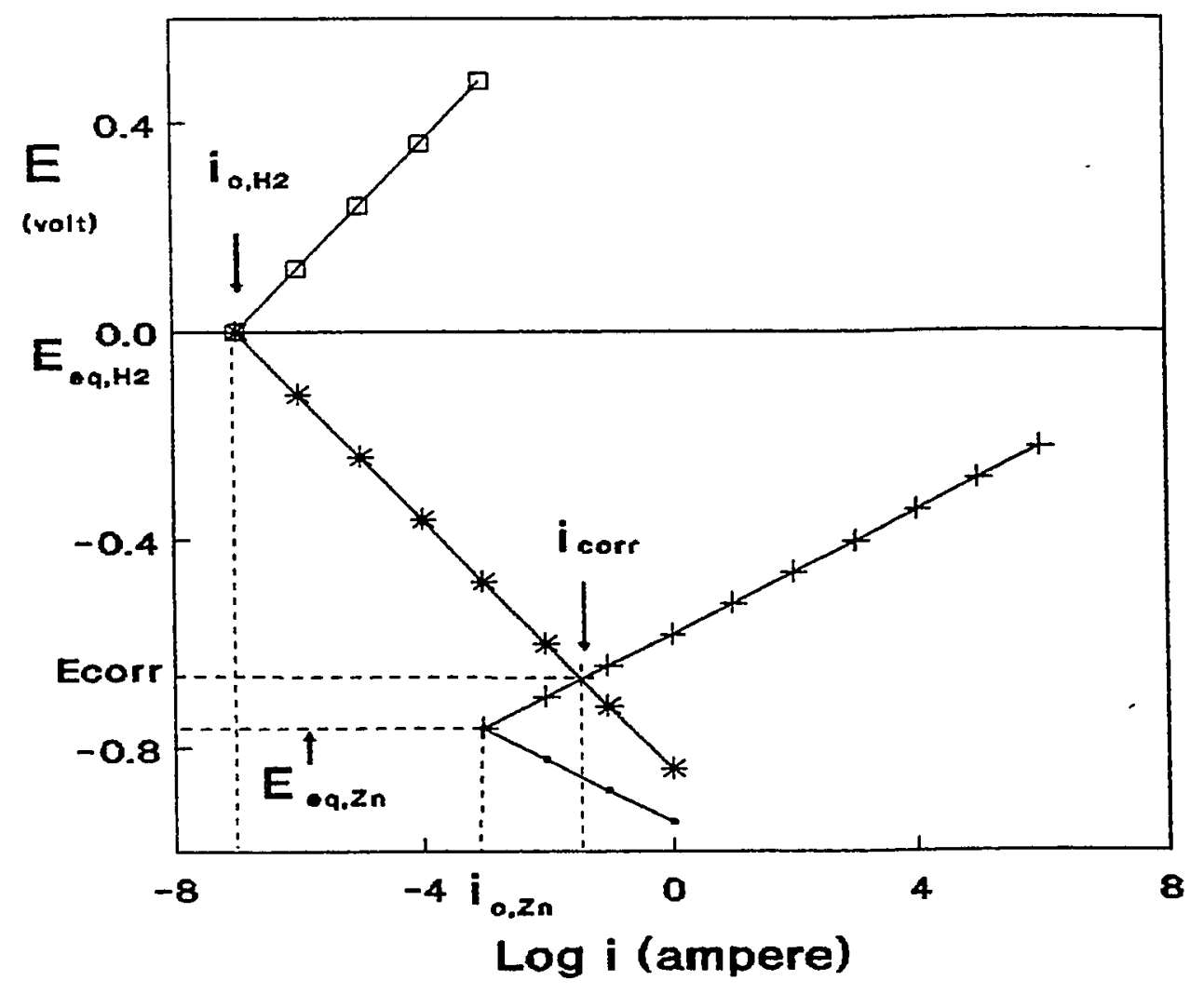

- Zn red + Zn oxi * H2 red $\because \mathrm{H} 2$ oxi

Eigure 10. The electrode potential $\mathrm{E}$ of $\mathrm{zinc}$ in deaerated water at $25^{\circ} \mathrm{C}$. 
at $25^{\circ} \mathrm{C}$ is -0.763 volts.

(2) From its definition, B is proportional to temperature in Kelvin. Since $B$ for hydrogen evolution at $25^{\circ} \mathrm{C}$ is 0.12 volts, its value at $85^{\circ} \mathrm{C}$ is therefore 0.144 volts. Similarly, B for zinc oxidation at $85^{\circ} \mathrm{C}$ is 0.072 volts, since its value at $25^{\circ} \mathrm{C}$ is 0.06 volts.

(3) In the absence of published values for the temperature dependence of $j_{0}$, it is necessary to assess its effect in corrosion potential qualitatively. The value of $j_{0}$ is expected to increase with increasing temperature. However, the relative rate of increase of $j_{0}$ for hydrogen evolution and for zinc oxidation will determine the final value of the corrosion potential. Given the uncertainties, it is not possible at this time to assess the effect of changes in $j_{0}$ in the corrosion potential. Experimental work in the temperature dependence of $j_{0}$ is therefore required.

The corrosion potential of zinc in deaerated water at $85^{\circ} \mathrm{C}$ can be calculated with the assumption that the temperature dependence of $j_{0}$ for the hydrogen evolution and the zinc oxidation are all equal to a constant $c$, and that the area of the cathode and the anode are also equal. Substituting the values of $E_{e q}, \beta$, and $j_{0}$ for hydrogen evolution and zinc oxidation at $85^{\circ} \mathrm{C}$ into Eqs.(18) and (19), respectively, give the following two equations: 


$$
\begin{aligned}
& E=-0.144 \log \left(\left|j_{a} / c\right|\right)-0.956 \text { volts } \\
& E=0.072 \log \left(\left|j_{c} / c\right|\right)-0.489 \text { volts }
\end{aligned}
$$

From the mixed-potential theory, when $j_{a}$ and $j_{c}$ are equal in magnitude, $E$ is the corrosion potential. Therefore, the corrosion potential for zinc can be obtained from the combination of Eqs(52) and (53), and is -0.645 volts. This value is much smaller than the standard electrochemical potential of iron at $25^{\circ} \mathrm{C}$, i.e., -0.440 volts. Therefore, corrosion potential of zinc would be always anodic to steel in deaerated waters for temperatures up to $85^{\circ} \mathrm{C}$.

\section{7-1-3 Corrosion Potential of Zinc in Aerated Water}

Previous investigators ${ }^{(3-9)}$ found that the corrosion potential reversal between zinc and iron in aerated water occurred only when temperature of the electrolyte increased up to $60^{\circ} \mathrm{C}$ or more. They concluded that this corrosion potential reversal was due to the ennoblement of zinc. Therefore, the two conditions that must be met for the corrosion potential between zinc and iron to reverse are therefore:

(1) the presence of dissolved oxygen, i.e., aerated waters, (2) a temperature equal to or greater than $60^{\circ} \mathrm{C}$.

These two conditions are discussed separately in the following sections. 
7-2 Effect of Dissolved Oxygen on Corrosion Potential of zinc

The main cathodic reaction for zinc in aerated non-acidic waters is the reduction of dissolved oxygen, i.e., as shown below:

$$
\mathrm{O}_{2} \text { (dissolved) }+2 \mathrm{H}_{2} \mathrm{O}(1)+4 \mathrm{e}^{-}=4 \mathrm{OH}^{-}(\mathrm{aq})
$$

The standard electrochemical potential at $25^{\circ} \mathrm{C}$ for $\mathrm{Eq} \cdot(25)$ is 0.401 volts, which is much more positive than that of zinc at the same temperature, which is -0.763 volts. When oxygen reduction occurs, the $\mathrm{OH}^{-}$combines with the $\mathrm{Zn}^{2+}$ from zinc dissolution, resulting in $\mathrm{Zn}(\mathrm{OH})_{2}$ formation on the zinc surface. The formation of zinc hydroxide on the zinc electrode changes the relative areas of cathode and anode, and thus affects the corrosion potential of zinc, as discussed in Section 2-6.

If the areas of the anode and cathode were to remain the same under all conditions, then there will be no reversal in the corrosion potential. This can be demonstrated by considering only oxygen polarization effects on the corrosion potential of the zinc electrode. Since oxygen is only very slightly soluble in water, its reduction is usually diffusion controlled ${ }^{(31)}$. In air-saturated non-agitated solutions, the limiting diffusion current density for oxygen reduction is 
approximately $1 \mathrm{~A} / \mathrm{m}^{2}(31)$. Therefore, the maximum polarization of oxygen on the zinc electrode occurs when the current density flowing through the zinc electrode equals the limiting diffusion current density, $i_{L}$, of dissolved oxygen. The maximum of the electrode potential, E, which was given in Eq. (19), and is repeated here,

$$
E=B_{a} \log \left(\left|i / i_{0}\right|\right)+E_{e q}
$$

occurs at maximum $B_{a}$ and minimum $i_{0}$. For the $\mathrm{Zn}^{2+} \mid \mathrm{Zn}$ system at $25^{\circ} \mathrm{C}$, as can be seen from Table $2, \mathrm{E}_{\mathrm{eq}}$ is -0.763 volt, maximum $\beta_{a}$ is 0.06 volt, and minimum $j_{0}$ is $10^{-3} \mathrm{~A} / \mathrm{m}^{2}$. Substituting these values into $\mathrm{Eq} \cdot(19)$ gives

$$
E=0.06 \times \log (|j|)-0.583 \text { volts }
$$

The maximum corrosion potential of zinc is -0.583 volts which is obtained by letting the value of $j$ in Eq. (54) equal to $i_{L}$ of oxygen reduction, i.e., $1 \mathrm{~A} / \mathrm{m}^{2}$. This maximum corrosion potential of zinc is more negative than the standard electrochemical potential of iron which is -0.440 volts at $25^{\circ} \mathrm{C}$. Therefore, when the areas of anode and cathode are equal, the corrosion potential of zinc is anodic to iron.

Next, consider the effect of oxygen reduction on the relative areas of anode and cathode. When a piece of zinc is 
dipped in an aerated water, corrosion of zinc starts, and corrosion products are formed on the zinc surface. If the corrosion process continues, the zinc surface covered by the corrosion products increases, resulting in the decrease of both anodic and cathodic areas. If the corrosion process continues further, most of zinc surface will be, finally, covered by the corrosion products. However, there must be some area which is not covered by corrosion products, otherwise zinc will be protected by the corrosion products from further corrosion. When most of the zinc surface is covered by corrosion products, the cathodic reaction proceeds at suitable pores in the corrosion products ${ }^{(7)}$. Therefore, the ratio of anode to cathode area decreases. As a result, the corrosion potential of zinc increases. The theoretical reason for this process was discussed in section 2-6.

Equation (54) can also be modified to calculate the minimum area ratio of cathode to anode required to raise the corrosion potential of zinc up to the standard electrochemical potential of iron at $25^{\circ} \mathrm{C}$, i.e., -0.440 volt. Suppose the area ratio of cathode to anode is $r$, i.e., anode area is $1 \mathrm{~m}^{2}$ and cathodic area is $x$ meter $^{2}$, then the limiting diffusion current of oxygen reduction will increase to $r$ ampere, since the limiting diffusion current density is $1 \mathrm{~A} / \mathrm{m}^{2}$. Substituting $j=r$ and $E=-0.440$ into $E q \cdot(54)$ gives $r=242$. That is, the area ratio of cathode to anode has to be at least 
242 in order to raise the corrosion potential of zinc in aerated water at $25^{\circ} \mathrm{C}$ up to the standard electrochemical potential of iron at the same temperature. Since the galvanic protection of iron offered by zinc at room temperature is beyond question, this result indicates that the area ratio of cathode to anode is less than 242 at room temperature, and no corrosion potential reversal between zinc and iron occurs at room temperature.

Although the effect of dissolved oxygen can raise the corrosion potential of zinc, it cannot alone account for the much more positive corrosion potential of zinc in aerated hot waters. The dissolved oxygen is greater at room temperature than in hot solutions, and if oxygen were the only factor, the most positive potentials would be expected to occur in cold solutions ${ }^{(7)}$. Therefore, there must be some other factor which accompanies, with the oxygen effect, to shift the corrosion potential of $\mathrm{zinc}$ cathodic to iron.

\section{7-3 Effect of Temperature on Corrosion Potential of zinc}

As discussed in Chapter 6, the effect of temperature alone cannot shift the standard electrochemical potential of zinc to a value more positive than that of iron. It must be accompanied by polarization effects caused by the species in solution. Therefore, in discussing the corrosion potential reversal between $\mathrm{Zn}$ and $\mathrm{Ee}$, temperature is a secondary factor, 
the primary factor being dissolved oxygen and solution composition ${ }^{(8)}$.

Temperature changes the corrosion potential of zinc mainly by affecting the nature of the corrosion products formed on the zinc surface. Since different kind of corrosion products have various porosity and electrical conductivity, the effective areas ratio of the cathode to the anode would be different. This in turn changes the corrosion potential of zinc.

\section{7-3-I Temperature Effect on Eormation of Corrosion Product}

Grubitsch and $I 11 i^{(32)}$ proposed that the corrosion product of zinc in cold aerated waters is zinc hydroxide, which may change to zinc oxide when the water temperature is raised to $60^{\circ} \mathrm{C}$. At this temperature the newly formed corrosion product is zinc oxide. The transformation reaction of zinc hydroxide to zinc oxide is

$$
\mathrm{Zn}(\mathrm{OH})_{2}(\mathrm{~s})=\mathrm{ZnO}(\mathrm{s})+\mathrm{H}_{2} \mathrm{O}(1)
$$

Calculation of the standard free energy change of Reaction (55) will give the information about the possibility of this transformation. Table 13 is a tabulation of the standard Gibbs free energy change that accompanies this reaction, for the temperature range of 20 to $80^{\circ} \mathrm{C}$. As can be seen from this 
Table 13. Standard Gibbs Free energy change of zinc hydroxide and zinc oxide transformation reaction at $20^{\circ} \mathrm{C} \leq \mathrm{T} \leq 80^{\circ} \mathrm{C}$.

\begin{tabular}{cc}
\hline Temp. $\left({ }^{\circ} \mathrm{C}\right)$ & Standard Eree energy change(cal/mole) \\
\hline & \\
20 & -688 \\
30 & -724 \\
40 & -760 \\
50 & -833 \\
60 & -905 \\
70 & -978 \\
80 & -1051 \\
\hline
\end{tabular}

* Transformation reaction: $\mathrm{Zn}(\mathrm{OH})_{2}(\mathrm{~s})=\mathrm{ZnO}(\mathrm{s})+\mathrm{H}_{2} \mathrm{O}(1)$ 
table, zinc hydroxide is more likely to transform to zinc oxide at higher temperatures. However, it should be noted that the absolute magnitude of the driving force is extremely small. Further, it should also be pointed out that the computed results are within the error margins of the data used for the calculations. It cannot, therefore, be said with absolute certainty that zinc hydroxide will transform to zinc oxide, though it is most likely to do so.

Possible effects of the $\mathrm{pH}$ of the solution on this reaction was also examined. The computations are contained in Appendix E. It was found that the $\mathrm{pH}$ of the solution does not affect this equilibrium.

Gilbert ${ }^{(7)}$ found by visual examination of corroded zinc specimens in aerated waters, and reported that in cold waters the anodic areas were fairly wide spread, while in hot waters the anodic areas were fewer and smaller. This may indicate the corrosion products formed in hot waters offer better protection to zinc than those formed in cold waters. Therefore, comparison of Pilling-Bedworth ratios of zinc oxide and zinc hydroxide may give some information about the kind of corrosion products formed in the cold and hot waters.

The Pilling-Bedworth $(P-B)$ ratio is defined as the volume ratio of corrosion product and metal per atom of metal, as given by the following equation: 


$$
\mathrm{P}-\mathrm{B} \text { ratio }=\mathrm{M}_{\mathrm{c}} \mathrm{d} / \mathrm{nMd}_{\mathrm{C}}
$$

where $M_{C}$ and $M$ are the molecular weights of the compound and the metal, respectively;

$d_{c}$ and $d$ are the densities of the compound and the metal, respectively;

$\mathrm{n}$ is the number of the metal atom per molecule of compound. In general, corrosion product with high P-B ratio (2 or 3) will not protect metal from further corrosion ${ }^{(33)}$. Table 14 lists the P-B ratios for some zinc compounds, as well as $\mathrm{Al}_{2} \mathrm{O}_{3}$ and $\mathrm{TiO}_{2}$, which are protective oxides for metallic aluminum and titanium, respectively. As can be seen from this table, the $\mathrm{P}-\mathrm{B}$ ratio for $\mathrm{Zn}(\mathrm{OH})_{2}$ is 3.56 , and this indicates that $\mathrm{Zn}(\mathrm{OH})_{2}$ is not a protective corrosion product. On the contrary, the Pilling-Bedworth ratio for $\mathrm{Zno}$ is 1.60 , indicating the $\mathrm{ZnO}$ is a better protective film than the $\mathrm{Zn}(\mathrm{OH})_{2}$. Therefore, the corrosion product in hot waters is possibly zinc oxide.

\section{7-3-2 Temperature Effect on Areas of Cathode and Anode}

At high temperatures zinc oxide becomes a n-type semiconductor owing to a slight excess of metallic ions in the lattice ${ }^{(34)}$. Although it is not possible that zinc oxide becomes a semiconductor at the low temperatures considered here, it is likely that zinc oxide offers better electrical 
Table 14. Pilling-Bedworth ratios for zinc compounds, aluminum oxide, and titanium oxide.

\begin{tabular}{ll}
\hline Species & Ratio \\
\hline $\mathrm{Zn}(\mathrm{OH})_{2}$ & 3.56 \\
$\mathrm{ZnO}$ & 1.60 \\
$\mathrm{Zn}(\mathrm{CO})_{3}$ & 3.10 \\
$\mathrm{Al}_{2} \mathrm{O}_{3}$ & 1.28 \\
$\mathrm{TiO}_{2}$ & 1.76 \\
\hline
\end{tabular}


conduction than zinc hydroxide ${ }^{(7)}$.

If the corrosion product on the surface of a single zinc electrode transforms from zinc hydroxide to zinc oxide when the temperature is raised to $60^{\circ} \mathrm{C}$ or above, then (1) the effective cathodic area will be enlarged due to the better electrical conduction of zinc oxide than hydroxide, since the cathodic reaction proceeds at suitable pores in the corrosion products $^{(7)} ;$ (2) the effective anode area will be reduced due to the better protection of the zinc surface by zinc oxide than by rins hydroxide. Therefore, the corrosion potential of zinc would be more positive if the temperature is raised to $60^{\circ} \mathrm{C}$ or more.

Erom the above discussion, it can be concluded that temperature affects the corrosion potential by transforming the corrosion product from zinc hydroxide to zinc oxide, thus causing an increase in the effective cathode area and a decrease in the anode area. This raises the corrosion potential of zinc, and thus results in the corrosion potential of zinc in hot aerated waters being positive to iron.

\section{7-4 Effect of Water Composition on Corrosion Potential of zinc}

Since the corrosion potential reversal between zinc and iron appears to be due to the ennoblement of zinc, it is necessary to discuss the effect of water composition on the corrosion potential of zinc. The zinc corrosion potentials 
have been found to vary over wide limits depending on the electrolyte composition ${ }^{(7.8)}$. In general, if the ions from the dissolution of a solute in water can combine with the zinc ions to form a surface deposit on the zinc electrode, then the corrosion potential of zinc can be expected to increase. On the other hand, if the ions coming from this solute do not combine with zinc ions to form insoluble compound(s), the corrosion potential of zinc would decrease. Besides the solubility effect of these solutes, their presence in water may also affect the porosities and the adherence of surface deposits on zinc surfaces, results in the change of the effective area ratio of the cathode to the anode, and therefore affect the corrosion potential of zinc. The effects of carbonates, bicarbonates, chlorides, and sulfates on the corrosion potential of zinc are discussed in the following sections.

Addition of carbonates or bicarbonates in the electrolyte, in which a single zinc electrode is dipped, had been found to increase the corrosion potential of the zinc $^{(4,5,8)}$. This may be explained by the formations of insoluble $\mathrm{Zn}\left(\mathrm{HCO}_{3}\right)_{2}$ and/or $\mathrm{ZnCO}_{3}$ compounds on the zinc surface, and thus decreasing the anode area of the zinc electrode, resulting in the increase of the corrosion potential of zinc.

Chlorides have been found to cause a shift of the corrosion potential of a single zinc electrode in the anodic direction ${ }^{(7,8)}$. The corrosive effect of chloride on zinc was 
related to the solubility of zinc chloride ${ }^{(34)}$. This high solubility of $\mathrm{ZnCl}_{2}$ deters the precipitation in situ of other corrosion products at the anodic area, and thus increases the effective area of the anode ${ }^{(8)}$. Moreover, the capability of chloride ions to penetrate metallic oxide films causes an increased number of anodic sites on a corroding metallic surface ${ }^{(36)}$. Therefore, the corrosion potential of zinc would be shifted in the anodic direction.

The effect of sulfates on the corrosion potential of a single zinc electrode had been found ${ }^{(8)}$ to be similar to that of chloride. However, sulfate addition is more effective in decreasing the corrosion potential of zinc than chloride addition $^{(8)}$. This was explained based on a finding that the corrosion products of zinc in sulfate solutions are more adherent and less gelatinous than in chloride solutions ${ }^{(35)}$. When the corrosion products are more adherent and less gelatinous, the effective cathodic area decreases since the cathodic reaction proceeds at suitable pores in the corrosion products $^{(7)}$. Therefore, sulfates are more effective in decreasing the corrosion potential of zinc than chlorides are. From the discussions in Sections 7-1,7-2,7-3, and 7-4, the effects of dissolved oxygen, temperature, and water composition on the corrosion potentials of iron and zinc can be summarized as follows:

(1) In the case of iron, hydrogen evolution dominates over 
oxygen reduction, since the exchange current density of oxygen reduction on iron electrodes is small as compared to that of hydrogen evolution $\left(10^{-10}\right.$ vs. $\left.10^{-3} \mathrm{amp} / \mathrm{m}^{2}\right)$. As a consequence, the corrosion potentials in deaerated and aerated waters are approximately equal. The corrosion potentials in aerated water at the temperature range of 40 to $60^{\circ} \mathrm{C}$ was found ${ }^{(8)}$ to be in the range of $0.36-0.45$ volts, negative to a $\mathrm{NHE}$ at $25^{\circ} \mathrm{C}$. Moreover, the corrosion potentials of this order of magnitude were also observed even though the composition of the water, i.e., the amount of solute in the water, was varied over wide limit ${ }^{(8)}$. Therefore, the corrosion potential of iron can be considered to be constant, as compared to that of zinc.

(2) In the case of zinc, the polarization of dissolved oxygen ennobles the zinc, and the corrosion products formed on the zinc surface cause an increase in the relative area ratio of the cathode to the anode. The formation of corrosion products on its surface thus enhances the ennoblement of zinc, a process which was initiated by polarization of the dissolved oxygen. When the temperature of water is raised to $60^{\circ} \mathrm{C}$ or more, the corrosion products are transformed from zinc hydroxide to zinc oxide ${ }^{(7)}$ which offers better protection than the former. This transformation further enhances the ennoblement of zinc, and thus resulting in the corrosion potential of zinc becoming more positive than that of iron. In general, the effect of water composition, i.e., the 
presences of solutes in water, on the corrosion potential of zinc is dependent on the solubility of compound(s) formed by the combination of zinc ions and ions existing in the water. If this compound is insoluble in water, then it will be formed on the zinc surface, resulting in the increase of the relative cathode to anode area ratio, and thus increasing the corrosion potential of zinc. On the contrary, if this compound is soluble, then the corrosion potential of zinc can be generally expected to be decreased. Moreover, these impurities also affect the porosity and adherence of surface deposit on zinc, and thus affect the corrosion potential of zinc.

\section{7-5 Interpretation of Results of Previous Investigations}

Schikorr ${ }^{(3)}$ found that zinc, in Berlin water containing CaO impurity, actually could become cathodic to iron after a short exposure above $60^{\circ} \mathrm{C}$, and that a protective film of $\mathrm{CaCO}_{3}$, was formed on the zinc sample, and not on the iron. This observed reversal of corrosion potential is due to the presence of the dissolved oxygen and the elevated temperatures, as discussed in sections 7-2 and 7-3. Eurthermore, the presence of $\mathrm{CaCO}_{3}$ films on the zinc surface accelerated the occurrence of this reversal, since its presence increases the relative area ratio of the cathode to the anode, as discussed in Section 7-4. 
Roters and Eisenstecken ${ }^{(4)}$ found that pure zinc, galvanized steel, or Zn-Fe alloys could become cathodic to iron, when they were coupled with a piece of iron and were immersed in distilled water. This occurred after 2 to 4 weeks exposure even at room temperature, particularly if carbonates were added to the solution. As was discussed in Section 7-4, the addition of carbonates decreases the anode area of the zinc electrodes, and thus results in the increase of the corrosion potential of zinc. If the concentration of the carbonates is high enough to decrease the anode to cathode area ratio below 242 , as discussed in section $7-2$, it would be possible that the reversal would occur even at room temperature.

Kenworthy and Smith ${ }^{(5)}$ found that in hot hard water, corrosion of the zinc on a galvanized steel sample was generally the worst in waters having the highest carbon dioxide content, and the least in waters free from carbon dioxide. This phenomenon can be explained by considering the effect of carbon dioxide on the stability of calcium bicarbonate, which usually exists in hard water. Carbonate requires excess carbon dioxide in water to stabilize it ${ }^{(37)}$. Insufficient carbon dioxide in water leads to the decomposition of the calcium bicarbonate, and results in the precipitation of calcium carbonate on the zinc surface. Therefore, the corrosion of zinc will decrease. On the 
contrary, if excess carbon dioxide is present, the $\mathrm{pH}$ value of the water will be slightly increased. This results in the increase of calcium carbonate dissolution, and thus increases the corrosion of zinc.

In a 15-year service test on cold and hot lime-treated Baltimore waters, Bonilla $a^{(6)}$ found that galvanized steel pipe pitted less deeply than black wrought iron pipe in cold water, but more deeply in hot water. Based on the findings of Gilbert ${ }^{(7)}$, it can be stated that the waters Bonilla used must have contained dissolved oxygen, which led to a reversal in the corrosion potential at higher temperatures. This reversal would have accelerated the corrosion of galvanized steels, thus resulting in deeper pitting than in black iron.

Gilbert ${ }^{(7)}$ found that in the absence of oxygen, zinc remained anodic to steel at temperatures up to $85^{\circ} \mathrm{C}$. As was demonstrated in section 7-1-2, the corrosion potential of zinc in deaerated waters are likely to be more negative than that of iron. However, this result is based on the assumption that the temperature dependence of exchange current density for the hydrogen evolution and the zinc oxidation on zinc electrode are equal. Experimental work on the temperature dependence of exchange current density is therefore required in oraer to assess this phenomenon quantitatively. In aerated solutions, Gilbert also found that a temperature of over $60^{\circ} \mathrm{C}$ was necessary for zinc to become cathodic to iron, and that on 
cooling below $60^{\circ} \mathrm{C}$ the zinc was found to become anodic to the steel once again. When the temperature is raised to $60^{\circ} \mathrm{C}$ or more, the corrosion products would transform from zinc hydroxides to zinc oxide which is a better conducting and a more protective film than the former. This results in the increase in the relative area ratio of cathode to anode, and thus shift the corrosion potential of zinc to be more positive than that of iron. However, the driving force for this transformation is small. When the temperature has fallen below $60^{\circ} \mathrm{C}$, the transformation is reversed, and thus zinc becomes anodic to steel once again. Gilbert also found that no potential reversal was observed when the zinc-steel couple was dipped in hot or cold solutions containing 0.00115 molar $\mathrm{KCl}$ or 0.0005 molar $\mathrm{K}_{2} \mathrm{SO}_{4}$. However, in hot solutions containing either $0.0001,0.001$, or 0.005 molar $\mathrm{NaHCO}_{3}$, reversals occurred. This may be explained by the fact that the presence of chlorides or sulfates in the electrolyte prevents the reversal, due to the high solubility of zinc chloride or zinc sulfate, while the presence of bicarbonates favors the occurrence of the reversal, due to the insoluble nature of zinc bicarbonates.

In general, the findings by Hoxeng and Prutton ${ }^{(8)}$ were similar to those by Gilbert ${ }^{(7)}$. However, Hoxeng and Prutton emphasized that the electrolyte composition played a more dominant role in the changes in the corrosion potential 
between zinc and iron than temperature. This is consistent with the finding that zinc and iron can reverse their corrosion potentials, even at room temperature, when the concentration of carbonates are sufficiently high ${ }^{(4)}$. Coupled with the presence of dissolved oxygen, this can lead to the ennoblement of the zinc. Without the polarization effect, the corrosion potential would be identical to the electrochemical potential. Since the standard electrochemical potential is only slightly dependent on the temperature, a reversal of potential would therefore not be expected in the absence of polarization. 
Chapter 8. CONCLUSION

The standard electrochemical potential of zinc was found to be more negative than that of iron in the temperature rarge of 20 to $80^{\circ} \mathrm{C}$. There was no reversal of this potential over the entire temperature range investigated. Moreover, these potentials were found to be only sightly dependent on temperature.

The potential which was found to be reversed by other investigators is the corrosion potential. This reversal can be attributed to the precipitation of corrosion products on the zinc surface, and thus affect the corrosion potential of the zinc. The reversal occurred in the simultaneous presence of dissolved oxygen and at elevated temperatures, typically $60^{\circ} \mathrm{C}$ or more. Oxygen polarization on the zinc surface was found to be a determining factor in the occurrence of the corrosion potential reversal between zinc and iron. Without the polarization of the dissolved oxygen in water, no corrosion potential reversal would be observed. Temperature was found to be of secondary importance. However, oxygen polarization alone, in the absence of elevated temperatures, is insufficient to raise the corrosion potential of zinc to a level where it would be cathodic to iron. At lower temperatures, e.g., room temperature, a sufficiently high carbonate concentration, in addition to the presence of 
dissolved oxygen, is necessary for a reversal of the corrosion potential to occur. It is possible that there might be other species which could have the same effect as the presence of carbonates. These have not been investigated.

Water composition was also found to play an important role in determining the occurrence of a reversal in the corrosion potential. The presence of chlorides or sulfates in the water prevents the reversal of corrosion potential between zinc and iron, while that of bicarbonates or carbonates favors this reversal.

The standard electrochemical potential of a metal is an inherent property on which temperature has only a negligible effect. On the other hand, the corrosion potential of a metal is strongly dependent on the polarization effect of the species existing in solution, and is thus strongly environment dependent. The electrochemical potential of zinc was found to be anodic to iron over the entire temperature range investigated, while the corrosion potential of zinc was found to be cathodic to that of iron in some particular solutions at elevated temperatures, typically $60^{\circ} \mathrm{C}$ or more. 


\section{REEERENCES}

1. Britton, S. C., "The Resistance of Galvanized Iron to Corrosion by Domestic Water Supplies", J. Soc. Chem. Ind., (London), Vol. 55, (1936) pp. 19T-22T.

2. Baylis, J. R., "Treatment of Water to Prevent Corrosion", Amer. Water Works Assoc., Vol. 27, No. 2, (1935) pp. 220-234.

3. Schikorr, G., "The Cathodic Behavior of Zinc Versus Iron in Hot Tap Water", Trans. Electrochem. Soc., Vol. 76, (1939) pp. 247-258.

4. Roters, H., and Eisenstecken, F., "Die Umpolung im Element Eisen-Zink durch Schutzschichtenbildung in w*Brigen Lssungen", Archiv Eisenhuttenw, Vol. 15, (1941) pp. 59-62.

5. Kenworthy, L., and Smith, M. D., "Corrosion of Galvanized Coatings and zinc by Waters Containing Free Carbon Dioxide", J. Inst. Met, Vol. 70, (1944) pp. 463-489.

6. Bonilla, C. F., "Pipe Service Tests on Baltimore Water", Trans. Electrochem. Soc., Vol. 87, (1945) pp. 237-254.

7. Gilbert, P. T., "The Corrosion of Zinc and Zinc Coated Steel in Hot Waters", Sheet Metal Ind., Vol. 25, (1948) pp. 2003-2012, 2243-2254, 2441-2460.

8. Hoxeng, R. B., and Prutton, C. F., "Electrochemical Behavior of Zinc and Steel in Aqueous Media", Corrosion, Vol. 5, (1949) pp. 330-338.

9. Hoxeng, R. B., "Electrochemical Behavior of Zinc and Steel in Aqueous Media--Part II", Corrosion, Vol. 6, (1950) pp. 308312 .

10. Bockris, J. O., and Reddy, K. N., Modern Electrochemistry, Vol. 2, Plenum Press, (1977) pp. 644-661.

11. Bockris, J. O., and Reddy, K. N., ibid., p. 1116.

12. Bockris, J. O., and Reddy, K. N., ibid., pp. 863-929, 1099-1107, and 1265-1314.

13. Uhlig, H. H., Corrosion and Corrosion Control, 2nd ed., John Wiley and Sons Inc., 1971, pp. 37-59.

14. Fontana, M. G., Corrosion Engineering, 3rd ed., McGrawHill Book Company, 1986, pp. 454-504. 
15. Bard, A. J., and Eaulkner, L. R., Electrochemical Methods, Fundamentals, and Applications, 1980, p. 103.

16. Bard, A. J., and Faulkner, L. R., ibid., p. 96.

17. Fontana, M. G., ibid., p. 460.

18. Fontana, M. G., ibid., p. 462.

19. West, J. M., Basic Corrosion and Oxidation, 2nd ed., John Wiley and Sons, p. 82 .

20. Myers, J. R., and Obrecht, M. F., "Potable Water System-Recognition of Cause Vital in Minimizing Corrosion", Materials Protection and Performance, Vol. 11, No. 4, (1972) p. 45.

21. Mihailov, Gr. and Iovchev, M., "Corrosion Studies of Galvanized Steel and Zinc in Soft Water at Various Temperatures", Metaliic Corrosion. 8th International Congress on Metallic Corrosion, Vol. 2, (1981) p. 1756.

22. Reyuela, J. J., "Corrosion by Potable Water--Influence of Temperature", International Congress on Metaliic Corrosion, Vol. 3, (1984) p. 603 .

23. Salvi, G. R., and deBethune, A. J., "The Temperature Coefficients of Electrode Potentials", J. Electro. Soc., Vol. 108, (1961) pp. 672-676.

24. Kubaschewski, O., and Alcock, C. B., Metallurgical Thermochemistry, 5th ed., Pergamon Press, 1979.

25. Wicks, C. E., and Block, F. E., Thermodynamic Properties of 65 Elements--Their Oxides, Halides, Carbides, and Nitrides, United states Government Printing Office, 1963.

26. Robie, R. A., Hemingway, B. S., and Eisher, J. R., Thermodynamic Properties of Minerals and Related Substances at $298.15^{\circ} \mathrm{K}$ and 1 Bar Pressure and at Higher Temperatures, United States Government Printing Office, 1978.

27. Hampel, C. A., ed., The Encyclopedia of Electrochemistry, Reinhold Publishing Cor., p. 433.

28. Robinson, R. A., and Stokes, R. H., "The Thermodynamics of Zinc Chloride Solutions", Trans. Faraday Soc., Vol. 36, (1940) pp. 740-748.

29. Randal1, M., and Frandsen, M., "The Standard Electrode Potential of Iron and the Activity Coefficient of Ferrous 
Chloride", J. Amer. Chem. Soc., Vol. 54, (1932) pp. 47-54.

30. Harned, H. S., and Owen, B. B., The Physical Chemistry of Electrolytic Solutions, 3rd Ed. Reinhold Publishing Corp., (1958) p. 645.

31. Eontana, M. G., ibid., p. 493.

32. Grubitsch, H., and I1li, O., Korr. und Metallschutz, Vol. 16, (1940) p. 197 .

33. Fontana, M. G., ibid., p. 506.

34. Massey, H. S. W., J. Sci. Instruments, Vol. 24, (1947) p. 220 .

35. Evans, U. R., Metallic Corrosion Passivity and Protection, Longmans, Green and Co., (1946) p. 359.

36. Evans, U. R., ibid., p. 22 .

37. Shreir, L. L., ed., Corrosion, Newnes-Butterworths, Vol. 1, (1976) P. 2-41. 


\section{BIBLIOGRAPHY}

1. Grubitsch, V. H., and Hilbert, F., "Pressure and Temperature Dependence of the Corrosion Potential of Zinc in Aqueous Electrolytes", Werkstoffe und Korrosion, Vol. 28, (1977) pp. 309-312.

2. Juchniewicz, R., et al. "Detection of Polarity Reversal of Zinc Coatings on Steel in Hot Water Systems", ibid., Vol. 2, (1981) p. 1966.

3. Mihailov, Gr., Iovchev, M., "Corrosion Studies of Galvanized Steel and Zinc in Soft Water at Various Temperatures." Metallic Corrosion. 8th International Congress on Metallic Corrosion, Vol. 2, (1981) p. 1754.

4. Obrecht, M. F., and Myers, J. R., "Performance and Selection of Materials for Potable Hot Water Service", Heating/ Piping/Air Conditioning, 1973, pp 53-59.

5. Radke, S. F., and Druelle, N., "Corrosion of Galvanized Steel Pipe in Hot and Cold Water Systems", Australian Corrosion Engineering, 1975, pp. 21-25.

6. Slunder, C. J., and Boyd, W. K., Zinc: Its corrosion resistance International Lead Zinc Research Organization, Inc. New York, 1983. 


\section{APRENDIX A}

Standard enthalpies $\mathrm{H}_{298}{ }_{+}$and standard entropies $\mathrm{S}_{298}^{0}$ of $\mathrm{zinc}$, iron and their compounds ${ }^{+}$.

\begin{tabular}{|c|c|c|}
\hline Species $^{*}$ & $\begin{array}{c}\mathrm{H}^{0} \\
\text { cal/mole }\end{array}$ & $\mathrm{s}^{0}{ }_{\mathrm{cal}}^{98} \mathrm{~mole} / \mathrm{K}$ \\
\hline $\mathrm{Zn}$ & 0 & 9.95 \\
\hline $\mathrm{Fe}$ & 0 & 6.52 \\
\hline $\mathrm{O}_{2}(\mathrm{~g})$ & 0 & 49.00 \\
\hline $\mathrm{H}_{2}(\mathrm{~g})$ & 0 & 31.21 \\
\hline $\mathrm{Zno}$ & -83800 & 10.43 \\
\hline $\mathrm{Zn}(\mathrm{OH})_{2}$ & -153660 & - \\
\hline FeO & -63200 & 14.05 \\
\hline $\mathrm{Fe}(\mathrm{OH})_{2}$ & -137200 & 21.00 \\
\hline $\mathrm{Ee}_{3} \mathrm{O}_{4}$ & -266900 & 36.20 \\
\hline $\mathrm{Fe}_{2} \mathrm{O}_{3}$ & -196300 & 20.90 \\
\hline $\mathrm{Ee}(\mathrm{OH})_{3}$ & -199000 & 25.00 \\
\hline $\mathrm{EeOOH}$ & -133600 & 14.20 \\
\hline $\mathrm{H}_{2} \mathrm{O}(1)$ & -68315 & 16.718 \\
\hline
\end{tabular}




\section{APPENDIX B}

Standard heat capacities of zinc, iron, and their compounds ${ }^{+}$.

$$
\mathrm{C}_{\mathrm{p}}^{\mathrm{o}}=\mathrm{a}+\mathrm{bT}+\mathrm{cT}^{-2}+\mathrm{d}
$$

\begin{tabular}{|c|c|c|c|c|}
\hline \multirow{2}{*}{ Species ${ }^{\star}$} & \multicolumn{4}{|c|}{$\mathrm{C}_{\mathrm{n}}$ (cal/mole degree $\mathrm{K}$ ) } \\
\hline & $\bar{a}$ & $b * 10^{4}$ & $c^{*} 10^{-3}$ & $\mathrm{~d}$ \\
\hline $\mathrm{Zn}$ & 5.35 & 24 & - & \\
\hline $\mathrm{Ee}$ & 8.873 & 14.74 & - & $-56.92 \mathrm{~T}^{-1 / 2}$ \\
\hline $\mathrm{O}_{2}(g)$ & 7.16 & 10 & -40 & \\
\hline $\mathrm{H}_{2}(\mathrm{~g})$ & 6.52 & 7.8 & 12 & \\
\hline $\mathrm{ZnO}$ & 11.71 & 12.2 & -218 & \\
\hline $\mathrm{FeO}$ & 12.38 & 16.2 & -38 & \\
\hline $\mathrm{Fe}(\mathrm{OH})_{2}$ & 17.567 & 194.87 & 43.8 & $-7.62 * 10^{-6} \mathrm{~T}^{2}$ \\
\hline $\mathrm{Fe}_{3} \mathrm{O}_{4}$ & 21.88 & 482 & - & \\
\hline $\mathrm{Fe}_{2} \mathrm{O}_{3}$ & 23.49 & 186 & -355 & \\
\hline $\mathrm{Ee}(\mathrm{OH})_{3}$ & 20.438 & 294.55 & 361.4 & $-1.01 * 10^{-5} T^{2}$ \\
\hline $\mathrm{H}_{2} \mathrm{O}(1)$ & 18.03 & - & - & \\
\hline
\end{tabular}

* Species is solid unless where indicated.

+ data after Ref. 24 and 25 . 


\section{APPENDIX C}

Formation reactions of $\mathrm{zinc}$ and iron compounds.

1

$\mathrm{Zn}(\mathrm{s})+1 / 2 \mathrm{O}_{2}$ (dissolved) $=\mathrm{ZnO}(\mathrm{s})$

2. $\quad \mathrm{Zn}(\mathrm{s})+\mathrm{O}_{2}$ (dissolved) $+\mathrm{H}_{2}(\mathrm{~g})=\mathrm{Zn}(\mathrm{OH})_{2}(\mathrm{~s})$

3. $\mathrm{Fe}(\mathrm{s})+1 / 2 \mathrm{O}_{2}$ (dissolved) $=\mathrm{FeO}(\mathrm{s})$

4. $\mathrm{Fe}(\mathrm{s})+\mathrm{O}_{2}$ (dissolved) $+\mathrm{H}_{2}(\mathrm{~g})=\mathrm{Fe}(\mathrm{OH})_{2}(\mathrm{~s})$

5. $\quad 3 \mathrm{Fe}(\mathrm{s})+2 \mathrm{O}_{2}$ (dissolved) $=\mathrm{Ee}_{3} \mathrm{O}_{4}(\mathrm{~s})$

6. $2 \mathrm{Fe}(\mathrm{s})+3 / 2 \mathrm{O}_{2}$ (dissolved) $=\mathrm{Fe}_{2} \mathrm{O}_{3}(\mathrm{~s})$

7. $\mathrm{Fe}(\mathrm{s})+3 / 2 \mathrm{O}_{2}$ (dissolved) $+3 / 2 \mathrm{H}_{2}(\mathrm{~g})=\mathrm{Fe}(\mathrm{OH})_{3}(\mathrm{~s})$

8. $\quad \mathrm{Fe}(\mathrm{s})+\mathrm{O}_{2}$ (dissolved) $+1 / 2 \mathrm{H}_{2}(\mathrm{~g})=\mathrm{FeOOH}(\mathrm{s})$ 


\section{ARPENDIX D}

Standard Gibbs free energy change of formation for zinc, iron, and compounds at $20^{\circ} \mathrm{C} \leq \mathrm{T} \leq 80^{\circ} \mathrm{C}$ (units:Kcal/mole).

\begin{tabular}{llllllll}
\hline $\mathrm{T}(\mathrm{C})$ & $\mathrm{Zn}(\mathrm{s})$ & $\mathrm{Fe}(\mathrm{s})$ & $\mathrm{O}_{2}(\mathrm{~g})$ & $\mathrm{H}_{2}(\mathrm{~g})$ & $\mathrm{FeO}(\mathrm{s})$ & $\mathrm{Fe}(\mathrm{OH})_{2}(\mathrm{~s})$ & $\mathrm{Fe}_{3} \mathrm{O}_{4}(\mathrm{~s})$ \\
\hline 20 & -2.9 & -1.9 & -14.4 & -9.2 & -67.3 & -143.4 & -277.5 \\
25 & -3.0 & -1.9 & -14.6 & -9.3 & -67.4 & -143.5 & -277.7 \\
30 & -3.0 & -2.0 & -14.9 & -9.5 & -67.5 & -143.6 & -277.9 \\
40 & -3.1 & -2.0 & -15.3 & -9.8 & -67.6 & -143.8 & -278.3 \\
50 & -3.2 & -2.1 & -15.8 & -10.1 & -67.8 & -144.0 & -278.6 \\
60 & -3.3 & -2.2 & -16.3 & -10.4 & -67.9 & -144.2 & -279.0 \\
70 & -3.4 & -2.3 & -16.8 & -10.7 & -68.1 & -144.5 & -279.4 \\
80 & -3.5 & -2.3 & -17.3 & -11.1 & -68.2 & -144.7 & -279.9 \\
\hline
\end{tabular}

\begin{tabular}{ccccccc}
$\mathrm{T}(\mathrm{C})$ & $\mathrm{Fe}_{2} \mathrm{O}_{3}(\mathrm{~s})$ & $\mathrm{Fe}(\mathrm{OH})_{3}(\mathrm{~s})$ & $\mathrm{ZnO}(\mathrm{s})$ & $\mathrm{Zn}(\mathrm{OH})_{2}(\mathrm{~s})$ & $\mathrm{H}_{2} \mathrm{O}(1)$ & $\mathrm{FeOOH}(\mathrm{s})$ \\
\hline 20 & -202.4 & -206.3 & -86.9 & -159.4 & -73.2 & - \\
25 & -202.5 & -206.5 & -86.9 & -151.8 & -73.3 & -116.8 \\
30 & -202.6 & -206.6 & -87.0 & -151.5 & -73.4 & - \\
40 & -202.9 & -206.8 & -87.1 & -150.9 & -73.6 & - \\
50 & -203.1 & -207.1 & -87.2 & -150.3 & -73.7 & - \\
60 & -203.3 & -207.4 & -87.3 & -149.6 & -73.9 & - \\
70 & -203.6 & -207.7 & -87.4 & -149.0 & -74.1 & - \\
80 & -203.8 & -208.0 & -87.5 & -148.4 & -74.3 & - \\
\hline
\end{tabular}

Error estimated to be $\pm 3 \mathrm{Kcal} / \mathrm{mole}$. 


\section{APPENDIX E}

Possible effects of the $\mathrm{pH}$ of solution on the $\mathrm{Zn}(\mathrm{OH})_{2}-\mathrm{ZnO}$ transformation reaction.

It was found that the $\mathrm{pH}$ of the solution does not affect the $\mathrm{Zn}(\mathrm{OH})_{2}-\mathrm{ZnO}$ transformation reaction. This can be demonstrated by first considering the $\mathrm{pH}$ effect on the stabilities of $\mathrm{Zn}(\mathrm{OH})_{2}$ and $\mathrm{ZnO}$, respectively, and then comparing their relative stabilities.

Consider the following reaction leading to the $\mathrm{Zn}(\mathrm{OH})_{2}$ formation:

$$
\mathrm{Zn}(\mathrm{s})+2 \mathrm{H}_{2} \mathrm{O}(\mathrm{l})=\mathrm{Zn}(\mathrm{OH})_{2}(\mathrm{~s})+2 \mathrm{H}^{+}(\mathrm{aq})+2 \mathrm{e}^{-}
$$

$$
\begin{gathered}
\text { The Gibbs free energy change, } \Delta G_{r \times n}, f \text { the reaction is } \\
\Delta G_{r \times n l}=\Delta G_{r \times n l}^{0}-4.606 R T(p H)
\end{gathered}
$$

where $\Delta G_{\text {rxnl }}^{0}$ is the standard free energy change of Reaction (1). This equation indicates that the stability of $\mathrm{Zn}(\mathrm{OH})_{2}$ is dependent on the $\mathrm{pH}$ of the solution. Similarly, the $\mathrm{pH}$ effect on the stability of $\mathrm{Zno}$ can be determined by considering the following reaction and its $\Delta \mathrm{G}_{\mathrm{rxn}}^{0}$. These are:

$$
\mathrm{Zn}(\mathrm{s})+\mathrm{H}_{2} \mathrm{O}(\mathrm{l})=\mathrm{ZnO}(\mathrm{s})+2 \mathrm{H}^{+}(\mathrm{aq})+2 \mathrm{e}^{-}
$$




$$
\Delta G_{\mathrm{rxn} 3}=\Delta \mathrm{G}_{\mathrm{rxn} 3}^{\mathrm{O}}-4.606 \mathrm{RT}(\mathrm{pH})
$$

Subtracting Reaction (1) from (2) gives

$$
\mathrm{Zn}(\mathrm{OH})_{2}(\mathrm{~s})=\mathrm{ZnO}(\mathrm{s})+\mathrm{H}_{2} \mathrm{O}(1)
$$

which is the transformation reaction between $\mathrm{Zn}(\mathrm{OH})_{2}$ and $\mathrm{ZnO}$. The Gibbs free energy of Reaction (5) is equal to. the substraction of Eq.(2) from (4), and is not $\mathrm{pH}$ dependent. Therefore, it can be concluded that the pH of the solution does not affect the equilibrium between zinc hydroxide and zinc oxide, although it affects the formation of each of them. 